\title{
Alkene Oligomerization via metallacycles: Recent Advances and Mechanistic Insights
}

Julien Petit ${ }^{\mathrm{a}, \mathrm{b}}$, Lionel Magna* ${ }^{\mathrm{b}}$, Nicolas Mézailles*a

\begin{abstract}
The transformation of ethylene and alkenes is of high importance for the chemical industry. In this review, we focus on selective alkenes transformation where metallacyclopentane is suspected or demonstrated to be involved in the reaction mechanism. In addition to the alkenes, the "classical" products of ethylene oligomerization, we also cover articles dealing with the synthesis of cyclobutane and butadiene derivatives, through the common metallacycle intermediate. We also present studies that help decipher the precise mechanism of the transformations, i.e. involving synthesis of postulated intermediates, labelling experiments and DFT calculations.
\end{abstract}

Keywords: metallacycle, oligomerization, alkene.

\section{Introduction}

Following Karl Ziegler's discovery of ethylene oligomerization by organoaluminium compounds in $1952,[1]$ production of linear $\alpha$-olefins (LAOs) rapidly became a major process in the petrochemical industry, with an annual worldwide production estimated around 6.2 million tons in 2018.[2] Depending on their alkyl chain length, LAOs can be used as starting materials in various applications such as comonomers in the polymer industry, detergents, surfactants or lubricants.

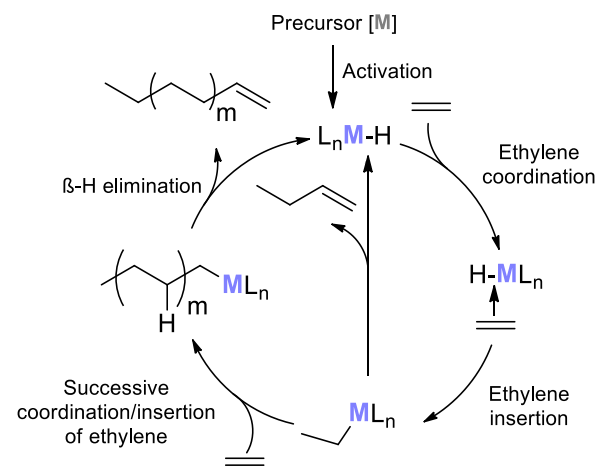

Scheme 1 - Cossee-Arlman mechanism.

Through a careful choice of catalyst (and co-catalyst), distribution of $\alpha$-olefins ("full range" processes: $\mathrm{C}_{4}-\mathrm{C}_{30}{ }^{+}$) or one single $\alpha$-olefin ("on purpose" processes: $\mathrm{C}_{4}, \mathrm{C}_{6}$ or $\mathrm{C}_{8}$ ) can be obtained. Homogeneous catalysts containing $\mathrm{Al}, \mathrm{Ni}$ or $\mathrm{Zr}$ are the most known species for the "full range" process at the industrial scale.

In this later case, the reaction mechanism is known as the "Cossee-Arlman" mechanism, firstly described in 1964 (Scheme 1).[3-5] Ethylene coordination followed by successive insertion into a nickel hydride or carbon bond implies the formation of alkenes after $\beta-\mathrm{H}$ elimination at the metallic center. It has been shown that ethylene coordination/insertion and $\beta-\mathrm{H}$ elimination from metal-alkyl chains of various lengths require similar energies, which rationalizes the low selectivity of such systems.

${ }^{a}$ J. Petit, Dr. N. Mézailles

Laboratoire Hétérochimie Fondamentale et Appliquée

Université Paul Sabatier, CNRS

118 Route de Narbonne, 31062 Toulouse (France)

E-mail:mezailles@chimie.ups-tlse.fr

${ }^{b}$ J. Petit, Dr. L. Magna

IFP Energies nouvelles, Rond-Point de l'Echangeur de Solaize BP3 


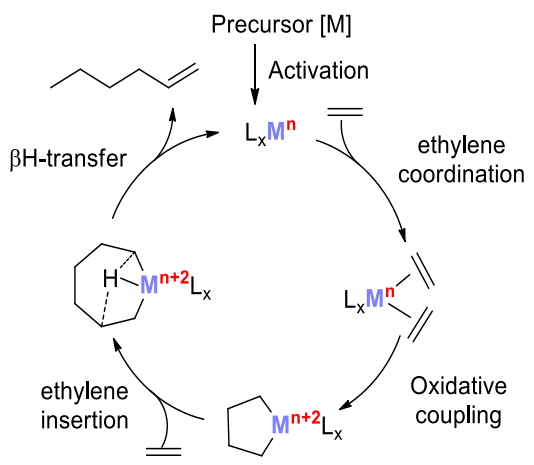

Scheme 2 - Metallacyclic pathway illustrated for 1-hexene synthesis

In recent years, the growing demand for short chain LAOs $\left(\mathrm{C}_{4}-\mathrm{C}_{8}\right)$, essentially applied as co-monomers for LLDPE (Linear Low Density Poly-Ethylene) manufacture, required the development of catalysts with higher selectivity for 1-butene, 1-hexene or 1-octene. The active species involved in this transformation, at least for selective 1-hexene and 1-octene production, are known to follow a metallacyclic pathway, first proposed by Briggs in 1989 (Scheme 2).[6] The generated metallic fragment is able to coordinate at least two ethylene molecules to proceed an oxidative coupling and form the metallacycle. By new ethylene insertion(s) and $\beta-\mathrm{H}$ transfer, an alkene is liberated.

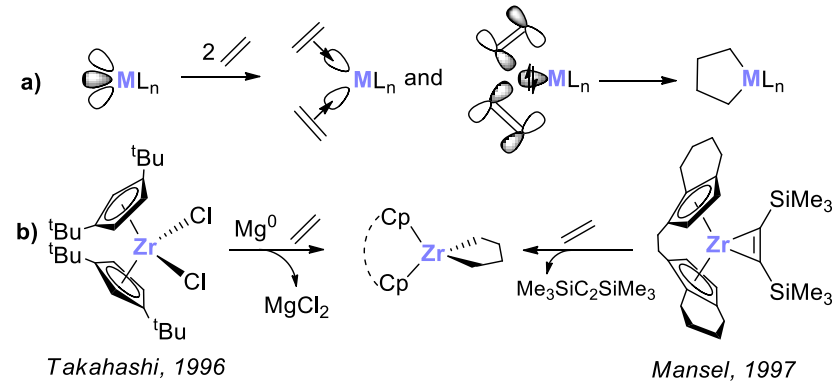

Scheme 3 - Requirements to obtain a metallacycle. Illustration with zirconocene fragments.

Chromium catalysts are, by far, the most studied systems for ethylene tri- and tetramerization[7] compared to other metals.[8,9] As illustrated in scheme 2, one of the key steps relies on the generation of a transition metal fragment that is able to induce oxidative coupling. This fragment has to gather two properties: a metallic center comprising two vacant orbitals to allow the coordination of two alkene molecules as well as two electrons in an orbital of appropriate symmetry to overlap with the in-phase combination of the pi* orbitals of ethylene (Scheme 3, a). As an illustration, thanks to the generation of the high energy zirconocene fragment $\left(\mathrm{Cp}_{2} \mathrm{Zr}^{\mathrm{II}}\right)$, Negishi demonstrated the possibility to reach a metallacycle from an en-yne.[10] Later, Takahashi's[11] and Mansel's[12] groups managed to isolate a metallacyclopentane, using a similar zirconium fragment, with appropriately modified Cp rings (Scheme $3, \mathrm{~b})$.

In this review, our goal is to provide an update in the mechanism studies of ethylene oligomerization since the last review proposed by McGuinness in 2011[8]. The aim is also to extrapolate the scope to other reactivities implementing a metallacyclic intermediate. In that way, we present all transition metal complexes that are able to achieve ethylene or 1-alkene oligomerization via metallacyclic intermediate(s) (scheme 4). 


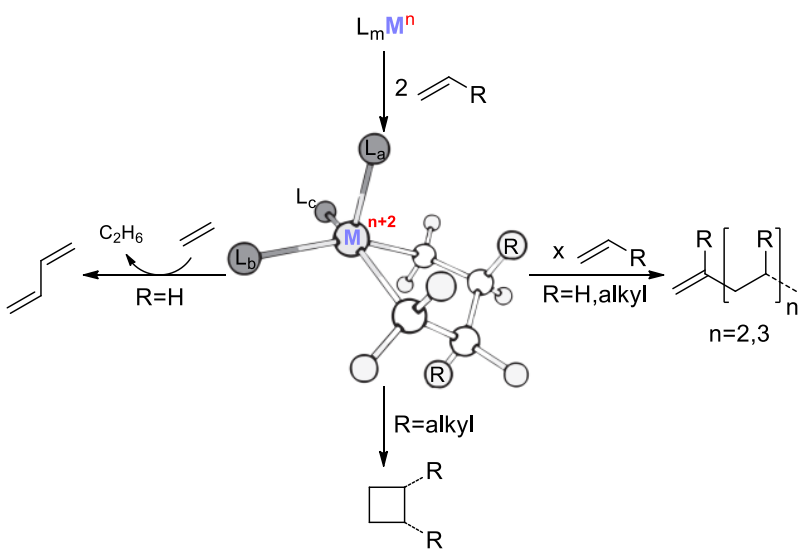

Scheme 4 - Topics covered in the review.

This survey will focus mainly on mechanistic studies, from the formation of hypothetical reactive fragment to the generation of different products: not only 1-alkene but also cyclobutane or butadiene derivatives as well. Ligand design or catalytic optimization is thus not central to our discussion and will therefore not be presented specifically except if it has a proven impact on the oligomerization mechanism followed. One of the goals of this review is also to show the existing methods to determine the operating mechanism in the oligomerization of alkenes. These discussions are intended to provide a guide for the researchers to define experiments that are suitable for the determination of the mechanism followed by their catalytic systems.

\section{From ethylene to 1-alkene}

In this section catalysts employed for selective ethylene oligomerization will be discussed. Only systems that are proposed or demonstrated to proceed via oxidative coupling of two ethylene molecules will be presented. In the latter case, mechanistic evidence will be highlighted for each complex. Note that in some cases, although selective oligomerization is observed, no consensus between Cossee-Arlman or metallacyclic mechanisms is obtained.

\subsection{Group 4: Titanium}

Several titanium complexes are reported to oligomerize ethylene selectively to give 1-butene or 1hexene. While there are many studies supporting a metallacyclic mechanism for activated titanium complexes producing 1-hexene, discussions about the mechanism followed by $\mathrm{Ti}(\mathrm{OR})_{4} / \mathrm{AlEt}_{3}$ systems producing 1-butene are still ongoing. Although a metallacycle was first proposed by Chauvin,[13] experimental[14] and theoretical[15] studies reported by McGuinness assessed the Cossee-Arlman mechanism to be the followed pathway.

\subsubsection{Half-titanocene.}

Half-titanocene was first known for its capacity to polymerize olefins. While tuning ligands for new reactivity in ethylene polymerization, a titanium catalyst was found to trimerize ethylene selectively through the metallacyclic mechanism. 

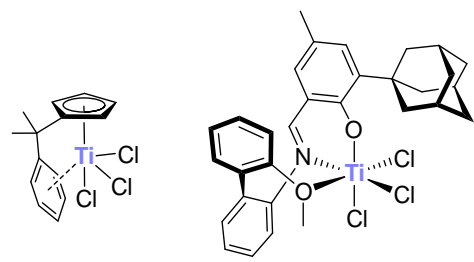

Scheme 5 - Titanium precursors active in ethylene trimerization.

The half-metallocene titanium complex $\left[\mathrm{Cp}^{*} \mathrm{TiMe}_{3}\right]$, after activation with $\mathrm{B}\left(\mathrm{C}_{6} \mathrm{~F}_{5}\right)_{3}$ in toluene, was shown by Pellechia in 1999 to copolymerize ethylene and 1-hexene, from a single ethylene feed.[16] This reactivity was explained by the generation of a highly reactive unsaturated cationic titanium(II) center and its stabilization with toluene. This $\mathrm{Ti}^{\mathrm{II}}$ species produces 1-hexene which is subsequently co-polymerized with ethylene by a $\mathrm{Ti}^{\mathrm{IV}}$-alkyl cationic complex, also generated in situ. Two years later, the half-titanocene complex featuring a pendant aryl group, was shown to produce 1-hexene up to $88 \%$ with only traces of polymer (PE), thereby confirming the hypothesis (Scheme 5, left).[17]

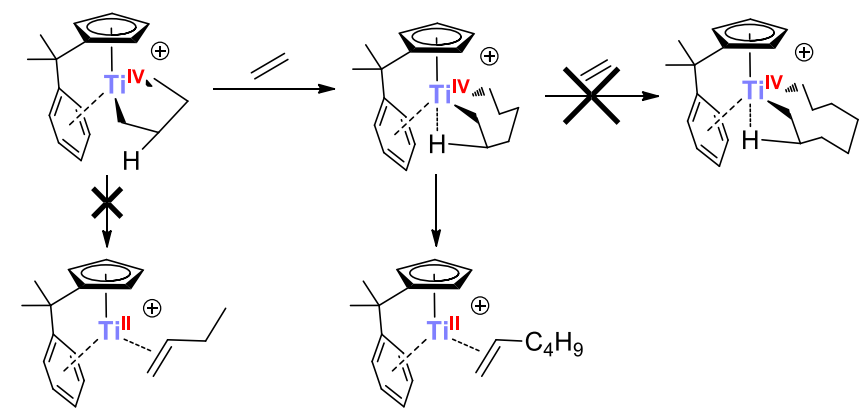

Scheme 6 - Illustration of the competition between $\beta-\mathrm{H}$ transfer and ethylene insertion, depending of the ring-flexibility of different metallacycloalkanes.

A wide variety of half-titanocene complexes with different pendant groups were then developed and studied through experimental and theoretical approaches. Discussions on these systems were condensed in previous reviews.[8,9] The key active species is a cationic titanium (II) complex. This fragment is obtained after methylation and cationization of $\left[\mathrm{Cp}^{\mathrm{Ph}} \mathrm{Ti}^{\mathrm{IV}} \mathrm{Cl}_{3}\right]$ to $\left[\mathrm{Cp}^{\mathrm{Ph}} \mathrm{Ti}^{\mathrm{IV}} \mathrm{Me}_{2}\right]^{+}$as demonstrated by Hessen and co-workers.[18] Insertion of ethylene in a Ti-Me bond followed by a $\beta-\mathrm{H}$ abstraction and a reductive elimination of an alkane, allows the reduction of the $\mathrm{Ti}^{(\mathrm{IV})}$ into $\mathrm{Ti}^{(\mathrm{II})}$. It affords the $\left[\mathrm{Cp}^{\mathrm{Ph}} \mathrm{Ti}^{\mathrm{II}}\right]^{+}$ fragment on which two ethylene molecules coordinate (similar mechanism is exposed on Scheme 8 with FI-Ti system).[19]

The formation of the first metallacyclopentane via oxidative coupling from two ethylene molecules is reported as facile.[20] The $\beta-\mathrm{H}$ transfer needed to form 1-butene is kinetically much slower than the insertion of a third molecule of ethylene, which rationalizes the absence of 1-butene in the product mixture (Scheme 6). From the metallacycloheptane, a more flexible ring, a facile $\beta$ - $\mathrm{H}$ transfer occurs, producing 1-hexene selectively. The $\beta-\mathrm{H}$ transfer is thus faster than the ethylene insertion to form the metallacyclononane.

Changing the phenyl pendant group always led to lower activities. Hemilability of the pendant ligand was highlighted as the key factor for the insertion of a new ethylene in the metallacycle (Scheme 7).[21] As an example, an ether pendant arm causes inactivity towards ethylene trimerization (Scheme 7).[22] Replacing the $\mathrm{Cp}$ group by an indenyle group led to even better activities without modifying the selectivity.[23] 

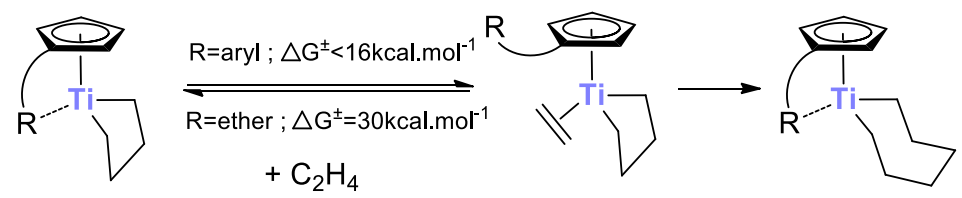

Scheme 7 - Activation barrier depending on pendant group on half-titanocene catalysts.

A theoretical study dealing with this system, focused on the influence of the MAO on the nature of the active species.[24] The introduction of a MAO-like cage as a counter-anion in the calculation does show the same energetic profile and geometries for the cationic fragments compared with DFT calculations ran with the cation moiety alone (without counter-anion).

\subsubsection{Phenoxy-imine -Generation of active species}

The second titanium complex efficient in ethylene trimerization are tridentate phenoxy-imine (FI) catalysts (Scheme 5, right), first reported by Mitsui Chemicals and Fujita's group in 2010.[25,26] The authors proposed a metallacyclic pathway after the in-situ generation of a cationic Ti(II) compound, similarly to the half-titanocene complexes. This hypothesis was confirmed by Bercaw and co-workers. They have first synthesized the cationic $\left[(\mathrm{FI}) \mathrm{Ti}^{\mathrm{IV}} \mathrm{Me}_{2}\right]^{+}$complex from $\left[\left(\mathrm{FI} \mathrm{Ti}^{\mathrm{IV}} \mathrm{Me}_{3}\right]\right.$ and $\mathrm{B}\left(\mathrm{C}_{6} \mathrm{~F}_{5}\right)_{3}$ (Scheme 8, a).[27] This cationic derivative released deuterated methane $\mathrm{CDH}_{3}$ when submitted to deuterated ethylene, providing a direct evidence of the $\beta-\mathrm{H}$ elimination followed by reductive elimination, leading to reduction of $\left[\mathrm{Ti}^{\mathrm{IV}}\right]^{+}$to $\left[\mathrm{Ti}^{\mathrm{II}}\right]^{+}$(Scheme $\left.8, \mathrm{~b}\right)$.

It is important to note that the reduction is reported to be the limiting step in the oligomerization process, both theoretically (more accurately, the insertion of ethylene in the Ti-Me bond is the most energetically demanding step)[28] and experimentally.[29] Indeed, the initial [(FI) $\left.\mathrm{Ti}^{\mathrm{IV}} \mathrm{Me}_{2}\right]^{+}$precursor is slowly consumed under ethylene while the activated $\left[(\mathrm{FI}) \mathrm{Ti}^{\mathrm{II}}\right]^{+}$already trimerizes ethylene (observed in ${ }^{1} \mathrm{H}$ NMR). After the addition of ethylene, the presence of $\mathrm{Ti}$ complexes in two oxidation states simultaneously in the medium is suspected to lead to the formation of inactive $\mathrm{Ti}^{\mathrm{III}}$ species by comproportionation. Accordingly, immobilization of the cationic $\left[(\mathrm{FI}) \mathrm{Ti}^{\mathrm{IV}} \mathrm{Me}_{2}\right]^{+}$on a MAO activated silica surface is reported to significantly decrease the comproportionation reaction, leading to a ten times higher initiation rate.[30] Solventless trimerization was also possible owing to the already activated catalyst on the surface.

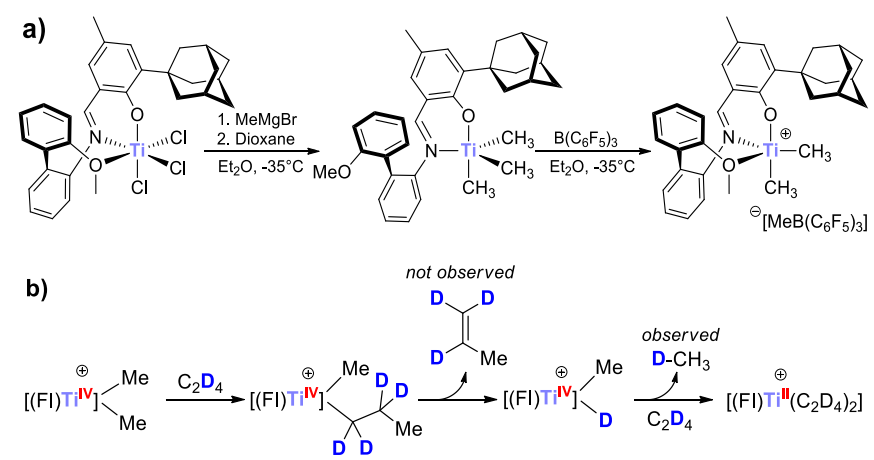

Scheme $8-$ a) Synthesis of $\left[(\mathrm{FI}) \mathrm{TiMe}_{2}\right]^{+}$precursor. b) One pathway for reduction from $\left[\mathrm{Ti}^{\mathrm{IV}}\right]^{+}$to $\left[\mathrm{Ti}^{\mathrm{II}}\right]^{+}$with deuterated ethylene accompanied with release of mono-deuterated methane.

NMR and EPR Spectroscopic studies, by Talsi and co-workers have highlighted the formation of $\mathrm{Ti}^{\mathrm{II}}$, $\mathrm{Ti}^{\mathrm{III}}$ and $\mathrm{Ti}^{\mathrm{IV}}$ mixtures from $(\mathrm{FI}) \mathrm{TiCl}_{3}$, which relative proportions depended on the aluminium cocatalyst.[31,32] Adding $\mathrm{AlR}_{3}(\mathrm{R}=\mathrm{Me}, \mathrm{Et})$ on $(\mathrm{FI}) \mathrm{TiCl}_{3}$ leaded to the formation of neutral $\mathrm{Ti}^{(\mathrm{II})}$ species according to NMR studies. Repeating the same experiment with one equivalent of $\left[\mathrm{CPh}_{3}\right]\left[\mathrm{B}\left(\mathrm{C}_{6} \mathrm{~F}_{5}\right)_{4}\right]$ 
induced the formation of a cationic Ti(II) species. A consequence of the use of MAO, in the absence of ethylene, is the distinct formation of $\left[\mathrm{Ti}^{\mathrm{II}}\right]^{+}$and $\left[\mathrm{Ti}^{\mathrm{IV}}\right]^{+}$species in solution, with a very small amount of $\left[\mathrm{Ti}^{\mathrm{III}}\right]^{+}$. On the other hand, the use of MMAO only results in the formation of $\left[\mathrm{Ti}^{\mathrm{III}}\right]^{+}$at room temperature. The obtained mixtures (resulting from (FI) TiCl $/ \mathrm{AlMe}_{3}, \quad(\mathrm{FI}) \mathrm{TiCl}_{3} / \mathrm{AlMe}_{3} /\left[\mathrm{CPh}_{3}\right]\left[\mathrm{B}\left(\mathrm{C}_{6} \mathrm{~F}_{5}\right)_{4}\right]$, (FI) $\mathrm{TiCl}_{3} / \mathrm{MAO}$ and $\left.(\mathrm{FI}) \mathrm{TiCl}_{3} / \mathrm{MMAO}\right)$, were reacted subsequently with ethylene. Only (FI) $\mathrm{TiCl}_{3} / \mathrm{AlMe}_{3} /\left[\mathrm{CPh}_{3}\right]\left[\mathrm{B}\left(\mathrm{C}_{6} \mathrm{~F}_{5}\right)_{4}\right]$ and $(\mathrm{FI}) \mathrm{TiCl}_{3} / \mathrm{MAO}$ catalytically trimerized ethylene, supporting a cationic titanium(II) complex as the active species (Scheme 9). However, when activating (FI)TiCl ${ }_{3}$ with MMAO under ethylene, production of 1-hexene is reported in a patent by Mitsui Chemicals, showing the importance of performing the activation under ethylene in this specific example.[26] When using alkyl aluminium $\mathrm{AlR}_{3}$ as cocatalyst, the $\mathrm{FI}$ transfer from $\mathrm{Ti}$ to $\mathrm{Al}$ was reported, leading to a polymerization catalyst.[33]

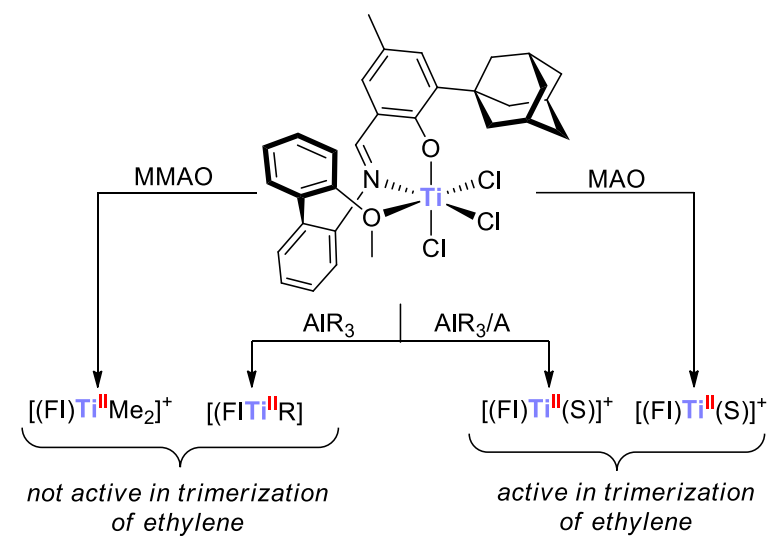

Scheme 9 - Results of the NMR study reported by Talsi and co-workers assessing a cationic $\mathrm{Ti}^{(\mathrm{II})}$ as the catalytically active species for ethylene trimerization. $\mathrm{R}=\mathrm{Me} ; \mathrm{A}=\left[\mathrm{CPh}_{3}\right]\left[\mathrm{B}\left(\mathrm{C}_{6} \mathrm{~F}_{5}\right)_{4}\right] ; \mathrm{S}=$ solvent or vacancy.

\subsubsection{Phenoxy-imine - metallacycle pathway.}

Bercaw and coworkers reported the formation of only four isotopologs of 1-hexene $\left(\mathrm{C}_{6} \mathrm{H}_{12}, \mathrm{C}_{6} \mathrm{H}_{8} \mathrm{D}_{4}\right.$, $\left.\mathrm{C}_{6} \mathrm{H}_{4} \mathrm{D}_{8}, \mathrm{C}_{6} \mathrm{D}_{12}\right)$ subsequent to the addition of a $1 / 1 \mathrm{C}_{2} \mathrm{H}_{4} / \mathrm{C}_{2} \mathrm{D}_{4}$ atmosphere on the cationic dimethyl $\left[(\mathrm{FI}) \mathrm{Ti}^{\mathrm{IV}} \mathrm{Me}_{2}\right]\left[\mathrm{MeB}\left(\mathrm{C}_{6} \mathrm{~F}_{5}\right)_{3}\right]$ complex.[27] As stated by the authors, "this observation rules out the Cossee-Arlman mechanism" due to the absence of H/D scrambling, thereby proving the metallacyclic pathway.

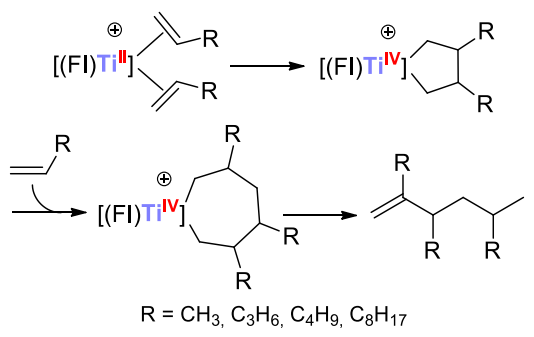

Scheme 10 - Metallacyclic pathway to the main 2,3,5-trialkyl-1-hexene isomer from different LAOs.

Theoretical DFT calculations corroborated these findings.[28] After reduction of $\left[(\mathrm{FI}) \mathrm{Ti}^{\mathrm{IV}} \mathrm{Me}\left(\mathrm{C}_{3} \mathrm{H}_{7}\right)\right]^{+}$to $\left[(\mathrm{FI}) \mathrm{Ti}^{\mathrm{II}}\left(\eta^{2}-\mathrm{C}_{3} \mathrm{H}_{6}\right)\right]^{+}$, coordination of ethylene in place of propene (ligand substitution) is reported as favorable and the oxidative coupling facile. The electron transfer from $\mathrm{Ti}$ to the two ethylene molecules results in the $\mathrm{C}-\mathrm{C}$ bond formation. Selectivity towards 1-hexene is due to two main reasons, identical to the ones presented above for the half-titanocene case. The first is the geometry constraint of the metallacyclopentane which disfavors the $\beta-\mathrm{H}$ transfer to form 1-butene. Conversely, the high flexibility of the metallacycloheptane obtained after ethylene insertion, results in a facile $\beta-\mathrm{H}$ transfer, i.e. at a 
significantly lower energy $\left(\Delta \mathrm{G}^{\neq}=19.3 \mathrm{kcal} . \mathrm{mol}^{-1}\right)$ compared to a new insertion of ethylene $\left(\Delta \mathrm{G}^{\neq}=38.2\right.$ kcal.mol $\left.{ }^{-1}\right)$. Finally, replacement of 1-hexene with ethylene is facile as well $\left(\Delta \mathrm{G}=-5.4 \mathrm{kcal}^{\mathrm{mol}} \mathrm{m}^{-1}\right)$ which allows selectivity in 1-hexene formation rather than co-trimerization of 1-hexene with two ethylene molecules.
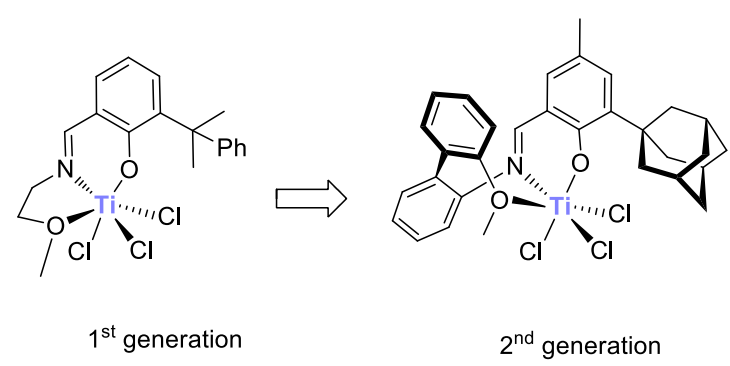

Scheme 11 - (FI)Ti trimerization catalyst synthesized by Fujita.

Bercaw and co-workers also demonstrated that $\left[(\mathrm{FI}) \mathrm{Ti}^{\mathrm{IV}} \mathrm{Me}_{2}\right]^{+}$could trimerize selectively a range of LAOs (propene to 1-decene) following the metallacycle pathway.[34] Indeed, trimers are formed in $>95 \%$ among which 2,3,5-trialkyl-1-hexene are obtained with a selectivity of $\mathrm{ca} 85 \%$ of the overall products. The high selectivity is explained by an oxidative coupling of two LAOs in the most sterically favorable manner, followed by the sterically appropriate insertion of a new LAO in the previously obtained titanacyclopentane. $\beta$-H transfer finally liberates the main isomer (Scheme 10).

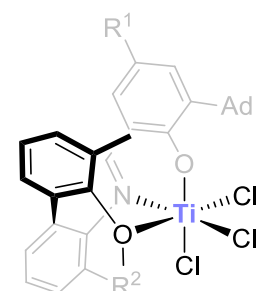

\begin{tabular}{|c|c|c|c|c|c|}
\hline$R^{1}$ & $R^{2}$ & Prod. & 1-hex & decenes & $P E$ \\
\hline $\mathrm{Me}$ & $\mathrm{H}$ & 20.0 & 91.0 & 7.6 & 1.3 \\
\hline $\mathrm{F}$ & $\mathrm{H}$ & 34.2 & 93.3 & 5.9 & 0.8 \\
\hline $\mathrm{OMe}$ & $\mathrm{H}$ & 16.6 & 87.2 & 11.1 & 1.7 \\
\hline $\mathrm{Me}$ & $\mathrm{Me}$ & 30.5 & 50.1 & 49.7 & 0.2 \\
\hline
\end{tabular}

Table 1 - Influence of different substituent on trimerization.

The FI ligand reported in these studies is a highly specific ligand incorporating a third constrained pendant ligand (OMe). This allows both the coordination of only one FI ligand as well as an octahedral geometry around titanium.[35] In their research on switching polymerization "(FI) ${ }_{2}$ Ti" catalysts to oligomerization catalysts, Fujita and coworkers first synthesized a version of the "(FI)Ti" featuring a flexible ether binding moiety (Scheme 11, left) which generated 34.5\% of 1-hexene together with $65.5 \%$ of PE, with a moderate activity of $0.1 \mathrm{~kg}$ of product $/ \mathrm{mmol}_{\mathrm{Ti}}^{-1} \cdot \mathrm{h}^{-1}\left(\mathrm{P}_{\mathrm{C} 2 \mathrm{H} 4}=0.8 \mathrm{MPa}, 25^{\circ} \mathrm{C}, 30 \mathrm{~min}\right) \cdot[28]$ Replacing the alkyl linker ( $1^{\text {st }}$ generation) between the imine and the ether by a bi-aryl ( $2^{\text {nd }}$ generation, Scheme 11, right) led to a drastic improvement of selectivity (up to $94.8 \%$ ) and activity (up to $31.9 \mathrm{~kg}$ of product $/ \mathrm{mmol}_{\mathrm{Ti}}{ }^{-1} \cdot \mathrm{h}^{-1}$ ). The authors proposed that the biaryl moiety induces a more conjugated structure of the phenoxy-imine moiety, resulting in higher performance of the catalyst, similarly to the results in polymerization by " $(\mathrm{FI})_{2}$ Ti”" catalysts.[36]

Changing the methyl substituent on the ether to ethyl, propyl and isobutyl gradually decreased the activity without modifying the selectivity.[28] McGuinness has reported that replacing this ether (OMe) by a thioether (SMe), while keeping the same ligand structure, led to a switch from oligomerization to polymerization ( $3 \%$ vs $87 \%$ ) and a ten times lower activity ( $24 \mathrm{vs} 236 \mathrm{~kg}_{\text {product }} \cdot \mathrm{mol}_{\mathrm{Ti}} \cdot \mathrm{h}^{-1}$ ) when activated by MAO.[37] Moreover, when the biaryl linker between the ether and the imine is replaced by an alkyl linker, the catalyst is almost inactive $\left(0.6 \mathrm{~kg}_{\text {product }} \cdot \mathrm{mol}_{\mathrm{Ti}} \cdot \mathrm{h}^{-1}\right)$. A switch from oligomerization to 
polymerization is also observed ( $3 \%$ vs $92 \%$ ), and it has to be noted that in the liquid fraction, 1-butene is the major product $(95 \%)$. This behavior highlights the role of the bi-aryl ether on the coordination of an ethylene molecule on the titanacyclopentane.

Besides the ether substituent, electronic effects were also evaluated in Fujita's work (Table 1).[28] Different substituents were introduced in the para-position of the ArO moiety. While the electrondonating methoxy group does not significantly modify the reactivity, fluorine does result in an increase of the reactivity without decreasing the selectivity. Fluorine is thought to promote a higher electronic flexibility between different oxidation states changes $\left(\mathrm{Ti}^{\mathrm{II}} / \mathrm{Ti}^{\mathrm{IV}}\right)$ in the metallacyclic pathway. Interestingly, adding a $\mathrm{Me}$ at $\mathrm{R}^{2}$ position of the biaryl spacer group induces an unexpected 1/1 mixture of 1-hexene and 2-butyl-1-hexene, the latter resulting from co-trimerization of 1-hexene and two ethylene molecules. It is proposed that in this case, replacement of 1-hexene by ethylene is more challenging.

Even though titanium complexes bearing FI (aryloxy-imine-biarylether) ligands can show excellent activities and selectivity in olefin trimerization, the system is quite sensitive. Any change in the ligand structure results in the annihilation of trimerization activity.[38] In addition to the parameters presented above, reaction temperature was shown to be important. Indeed, a temperature higher than $60^{\circ} \mathrm{C}$ favors polymerization.[39]

\subsection{Group 5: Vanadium, Niobium and Tantalum}

All metals of group 5 are able to selectively dimerize or trimerize ethylene, using the appropriate set of ligands. Nonetheless, discussions are still undergoing regarding the mechanism followed in some cases. In this section an overview of the different arguments supporting each mechanism is presented.

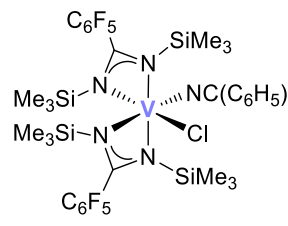

Scheme 12 - First vanadium precursor active in ethylene oligomerization

\subsubsection{Vanadium}

The first vanadium complex (Scheme 12) active in ethylene oligomerization was reported in 2000 by Hessen and co-workers.[40] Production of LAOs in a Schulz-Flory distribution attests the Cossee-Arlman mechanism.

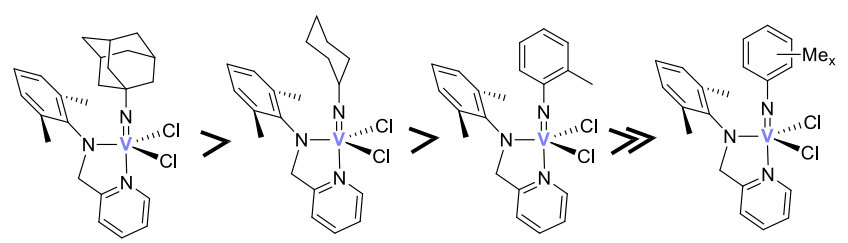

Scheme 13 - Comparison of different $\mathrm{V}^{\mathrm{V}}$ precursors for ethylene dimerization.

In 2010, Nomura and coworkers reported novel $\mathrm{V}^{\mathrm{V}}$ complexes bearing imido and (2-anilido)methylpyridine type ligands (

Scheme 13).[41] After activation, these complexes were reported to be excellent catalysts for dimerization of ethylene to 1-butene. With the "adamantyl imido" complex, a maximum TOF of 2730000 $\mathrm{h}^{-1}$ was obtained 10 minutes after activation with 1500 equivalent of MAO and yielded a selectivity of 
$97 \%$ in 1-butene. The same TOF was measured after $1 \mathrm{~h}$ of reaction, demonstrating the stability of the complex. Di-alkyl vanadium bearing the same ligands showed similar reactivity under identical conditions, supporting a common active species.[42]

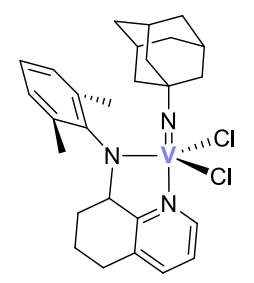

Scheme 14 - Structure of imido $\mathrm{V}^{\mathrm{V}}$ precursor.

Slight changes in the structure of the ligands revealed that its bulkiness plays an important role in the activity without altering its selectivity.[41] Aryl imido reduced drastically the activity (ten times lower) compared to cyclohexyl imido which was itself worse than adamantyl imido. Moreover, the activity of the arylimido derivatives depended on electronic and steric factors, with the ortho-Me being the most active.[43] All these considerations lead to the most active vanadium precursor for ethylene dimerization (Scheme 14).[44]

Further studies on this precursor showed a first order relationship between activity and ethylene concentration.[45] When activated by chloro-alkyl aluminium $\left(\mathrm{Et}_{2} \mathrm{AlCl}\right.$ or $\left.\mathrm{Me}_{2} \mathrm{AlCl}\right)$ instead of $\mathrm{MAO}$ the complex switched from dimerization to polymerization.[46] $\mathrm{Et}_{2} \mathrm{AlCl}$ is supposed to stay in the vanadium coordination sphere, preventing $\beta-\mathrm{H}$ elimination and thus favoring polymerization. On the other hand, using MAO or MMAO, the counter anion is proposed to be non-coordinating and bulky, which favors the dimerization (Scheme 15). Addition of $\left[\mathrm{CPh}_{3}\right]\left[\mathrm{B}\left(\mathrm{C}_{6} \mathrm{~F}_{5}\right)_{4}\right]$ and $\mathrm{Al}\left({ }^{\mathrm{i}} \mathrm{Bu}\right)_{3}$ on a dimethyl vanadium complex showed activity in both dimerization and polymerization (Scheme 16).[47] The role of $\mathrm{Al}\left({ }^{\mathrm{i}} \mathrm{Bu}\right)_{3}$ is unknown and a test without $\mathrm{Al}\left({ }^{\mathrm{i}} \mathrm{Bu}\right)_{3}$ has not been reported. Because of the dependence of ethylene pressure, of the aluminium cocatalyst, and the generation of a hypothetic cationic $\mathrm{V}^{\mathrm{V}}$ species, a CosseeArlman mechanism is suggested by the authors.

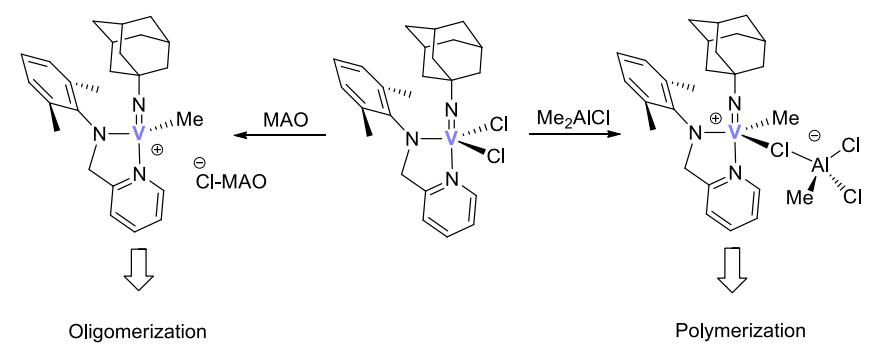

Scheme 15 - Influence of the cocatalyst on the reactivity.

${ }^{51} \mathrm{~V}$ NMR studies supported the formation of different species from the dichloride precursor depending of the activator (MAO, MMAO or $\mathrm{Et}_{2} \mathrm{AlCl}$ ).[46,47] In all cases, a cationic alkyl $\mathrm{V}^{\mathrm{V}}$ species is supposed as the first active species in oligomerization. To confirm this hypothesis, the dimethyl vanadium analogue was synthesized.[47] Activation of this compound by MAO shows similar activity and selectivity compared to the dichloride complex (Scheme 16). Its reactivity without co-catalyst (which would argue for or against a metallacyclic pathway) has not been reported to date.

V-edge XANES spectra of the dichloride and the dimethyl complexes, both reacted 10 eq. of MAO showed similarities with the dimethyl complex alone. Based on this experimental data, the authors proposed an alkyl $\mathrm{V}^{\mathrm{V}}$ complex as the active species.[48-50] However the catalyst is reported to be 
inactive under these conditions (activated by 10 eq. of MAO). It required 500 eq. to become active, and the nature of the $\mathrm{V}$ complex under these conditions has not been studied. Activation of the dimethyl complex with $\left[\mathrm{CPh}_{3}\right]\left[\mathrm{B}\left(\mathrm{C}_{6} \mathrm{~F}_{5}\right)_{4}\right]$ (1.5 eq.) and $\mathrm{Al}\left({ }^{\mathrm{i}} \mathrm{Bu}\right)_{3}(100$ eq.) led to activity in dimerization together with polymerization (446 and $42 \mathrm{~kg}$ of reacted ethylene per mol of $\mathrm{V}$ complex respectively), the latter proposed to be due to minor coordination of the generated counter anion (Scheme 16). Reaction of $\left[\mathrm{CPh}_{3}\right]\left[\mathrm{B}\left(\mathrm{C}_{6} \mathrm{~F}_{5}\right)_{4}\right]$ with the dimethyl $\mathrm{V}^{\mathrm{V}}$ complex in the presence of $\mathrm{Et}_{2} \mathrm{O}$ resulted in the formation of the cationic monomethyl $\mathrm{V}^{\mathrm{V}}\left[\mathrm{L}_{\mathrm{n}} \mathrm{V}^{\mathrm{V}}-\mathrm{Me}\left(\mathrm{Et}_{2} \mathrm{O}\right)\right]^{+}$complex (not active in catalysis), featuring a similar $\mathrm{V}$-edge XANES spectrum, further supporting a facile generation of an initial $\mathrm{V}^{\mathrm{V}}-\mathrm{Me}^{+}$species.

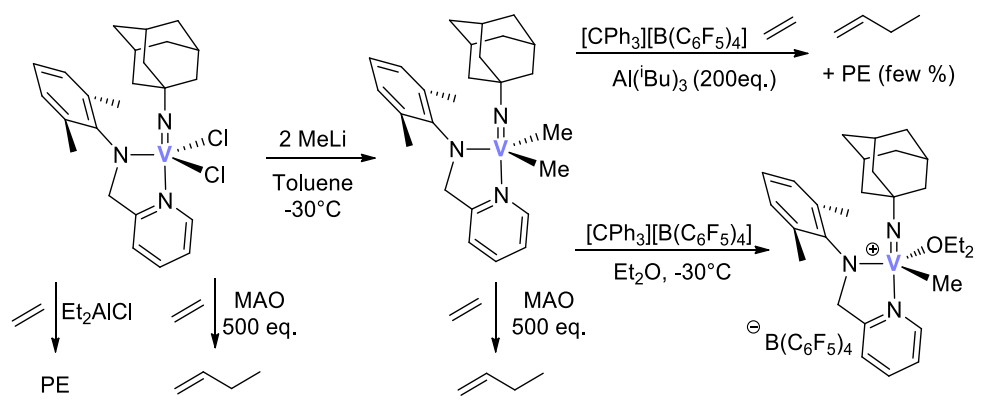

Scheme 16 - Evidence of a $\mathrm{V}^{\mathrm{V}}$ complex as an active species in ethylene dimerization.

In conclusion, although the formation of a cationic $\mathrm{V}^{\mathrm{V}}$ methyl complex upon activation was demonstrated, the proposed Cossee-Arlman mechanism lacks additional experiments to exclude the metallacyclic pathway. In particular, XANES experiments under catalytically competent conditions could rule out the intermediacy of a $\mathrm{V}^{\mathrm{III}}$ complex.

\subsection{Tantalum and Niobium}

In 2001, $\mathrm{TaCl}_{5}$ has been reported by Sen and coworkers to trimerize ethylene after activation with an alkylating agent into 1-hexene with high selectivity but low activity.[51] When $\mathrm{CD}_{3} \mathrm{Li}$ is used as an alkylating agent, $\mathrm{CD}_{3} \mathrm{H}$ is detected after the addition of ethylene, suggesting the formation of a Ta ${ }^{\mathrm{III}}$ active species for the trimerization of ethylene (Scheme 17, a).[51] $\mathrm{TaCl}_{3} \mathrm{Me}_{2}$ has been detected as the intermediate able to be reduced into $\mathrm{TaCl}_{3}$.[51] In 2003, DFT calculations supported the reduction of $\mathrm{Ta}^{\mathrm{V}} \mathrm{Cl}_{3} \mathrm{Me}_{2}$ to $\mathrm{Ta}^{\mathrm{III}} \mathrm{Cl}_{3}$ under ethylene as well as the metallacycle pathway being the operating oligomerization mechanism.[52] Mashima and coworkers, in a study from 2009, detected the metallacycle intermediate at $-10^{\circ} \mathrm{C}$ after the reduction of $\mathrm{TaCl}_{5}$ with an organic reducing agent under ethylene (Scheme 17, b).[53]

In 2012, Basset, Le Roux, Copéret and coworkers synthesized a silica supported tantalum catalyst for ethylene oligomerization (Scheme 18, a).[54] $\mathrm{Me}_{3} \mathrm{TaCl}_{2}$ was used as the homogeneous precursor and then grafted on a silica surface (SBA15-700), by alkane metathesis. Two isomeric species $\mathrm{Me}_{2} \mathrm{Cl}_{2} \mathrm{Ta}^{\mathrm{V}}(\mathrm{O}-\mathrm{Si} \equiv)$ were detected according to surface NMR analyses.

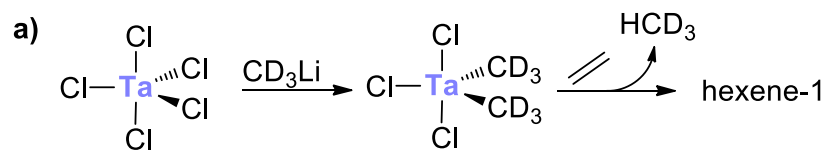




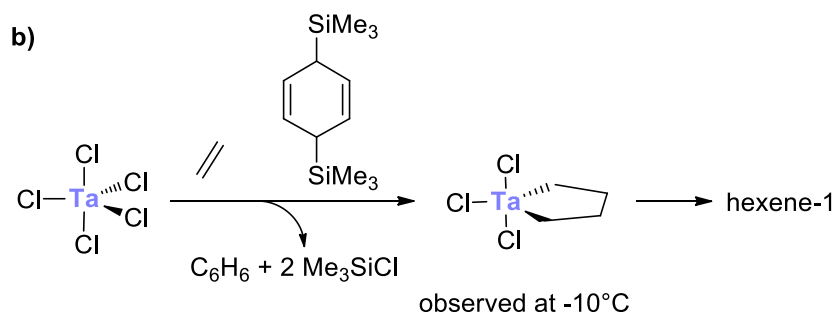

Scheme 17 - Proofs of the generation of a Ta ${ }^{\mathrm{III}}$ intermediate for ethylene oligomerization.

These well-defined homogeneous-supported catalysts, under ethylene (50 bars, $60-100^{\circ} \mathrm{C}$ ), were reported to produce 1-hexene with activities $\left(160-375 \mathrm{~mol}_{\mathrm{C} 2 \mathrm{H} 4} \cdot \mathrm{mol}_{\mathrm{Ta}} \cdot \mathrm{h}^{-1}\right)$ and selectivity $(>80 \mathrm{wt} \%)$ similar to the homogeneous $\mathrm{TaCl}_{5}$ activated by alkylating agents (Scheme 18, b, left). A first-order dependence between ethylene pressure and 1-hexene productivity was measured. When the catalysis was followed by an in-situ GC detector, methane, ethane, butane and propylene are detected at the beginning of the reaction which is an indirect evidence for reduction of $\mathrm{Ta}^{\mathrm{V}}$ in $\mathrm{Ta}^{\mathrm{III}}$. These observations confirm Mashima, Houk and Sen results that a non-alkylated $\mathrm{Ta}^{\mathrm{III}}$ species can oligomerize ethylene and promote oxidative coupling of two ethylene molecules.

a)

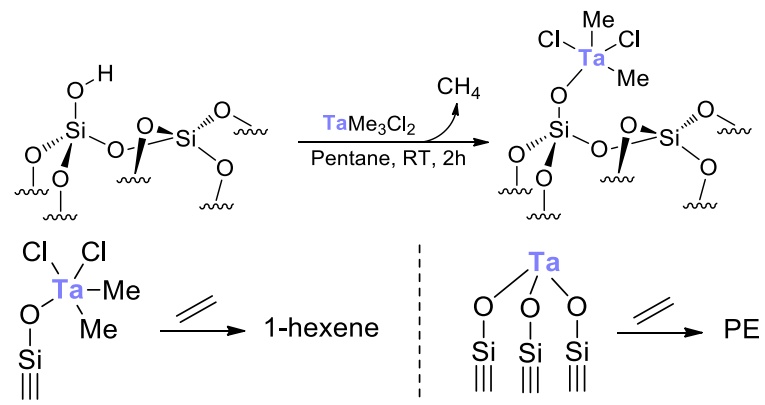

Scheme 18 - Experimental results of different tantalum grafted on silica surfaces.

One year later, Basset and co-workers tested a Ta ${ }^{\mathrm{III}}$ center supported on silica surface, $\mathrm{Ta}^{\mathrm{III}}(\mathrm{OSi} \equiv)_{3}$, in ethylene oligomerization.[55] To their surprise, the catalyst only produced PE under ethylene without activator (Scheme 18, b, right). In order to understand this reactivity, DFT calculations were carried out with different $\mathrm{Ta}^{\text {III }}$ silica supported models. Insertion of two ethylene molecules in the initial tantalacyclopropane to form the metallacycloheptane is reported as facile. When comparing the relative barriers for insertion of a new ethylene versus the formation of 1 -hexene (via $\beta-\mathrm{H}$ transfer) with the $\mathrm{Ta}^{\mathrm{III}}(\mathrm{O}-\mathrm{Si} \equiv)_{3}$ systems, the insertion is kinetically favorable by $4.1 \mathrm{kcal} . \mathrm{mol}^{-1}$ corroborating polymerization

Scheme 19, a, top). On the other hand, in the case of $\mathrm{Cl}_{2} \mathrm{Ta}^{\mathrm{III}}(\mathrm{O}-\mathrm{Si} \equiv)$, the $\beta-\mathrm{H}$ transfer is favorable by 8.6 kcal.mol ${ }^{-1}$ compared to a new ethylene insertion (

Scheme 19, a, bottom). 

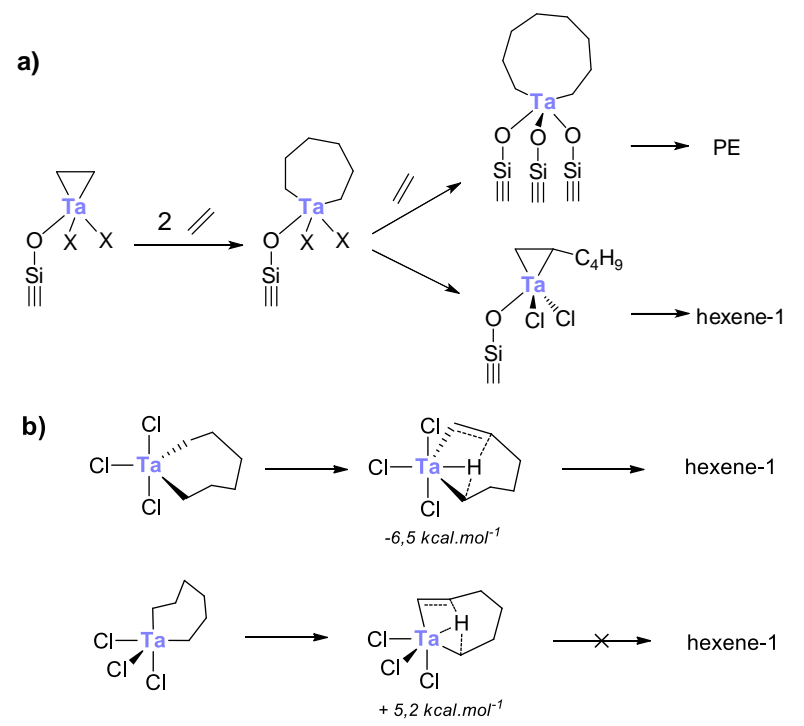

Scheme 19 - a) Comparative reactivity starting from two geometrically different supported metallacyclopropane. b) Difference of TS energies ( $\beta-\mathrm{H}$ transfer and ethylene insertion) and geometries starting from a trigonal bipyramid geometry (top) or a distorted bipyramid (bottom).

To explain this behavior, the authors compared the geometries requirements of the different supported complexes. They noted that "oligomerization catalysts" presented a trigonal bipyramid geometry whereas "PE catalysts" had a distorted square pyramid geometry. The first geometry implies the $\beta-\mathrm{H}$ transfer to happen in an equatorial plane while the second geometry forces the alkene being created to be out of the basal plane, due to geometry restrictions in the transition state. Thus, the geometry of the $\mathrm{ML}_{5}$ complex, enforced by the ligand, would be the key to obtaining a selective process (oligomerization or polymerization). To confirm this hypothesis, calculations were done on $\mathrm{TaCl}_{3}$ metallacyclic moiety with the two geometries and supported the fact that a bipyramid geometry induces PE formation while trigonal bipyramid results in 1-hexene formation (

Scheme 19, b). These considerations are to be taken into account for the synthesis of new precursors in this field, via ligand design.

Thereafter, in 2019, Dyers and co-workers reported the synthesis of imido tantalum precursors (Scheme 20) able to selectively dimerize ethylene to 1-butene (up to 80,7 wt\%) after activation with $\mathrm{EtAlCl}_{2}$. [56] The by-product is mainly 1-hexene. The very low PE production as well as the $100 \%$ selectivity in $1-$ butene in the butenes fraction is said to be in accordance with a metallacycle pathway although no mechanistic studies have been reported.

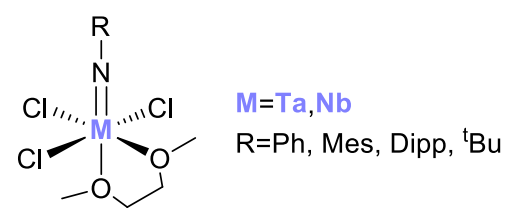

Scheme 20 - Different complexes of tantalum and niobium tested in ethylene oligomerization.

Analogous imido niobium precursors were synthesized and tested under the same conditions (Scheme 20).[56] Two main observations were noted : PE is produced in higher quantity (up to 70\%) and about $15 \%$ of butenes were isomerized to 2-butene. Secondly, the bulkier the imido moiety, the higher the PE 
production was. The steric effects are thus the major factor for the selectivity (Ph: $2.2 \mathrm{wt} \%$ of $\mathrm{PE}$ and 79.5 wt $\%$ of 1-butene in the liquid fraction, Mes: $25.1 \mathrm{wt} \% \mathrm{PE},{ }^{\mathrm{t}} \mathrm{Bu}: 62.7 \mathrm{wt} \% \mathrm{PE}$ and Dipp: $\left.70.7 \mathrm{wt} \% \mathrm{PE}\right)$.

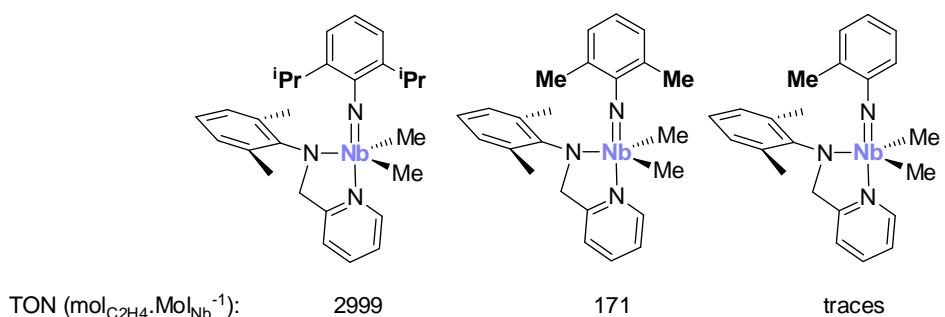

Scheme 21 - Overall TON of different complexes activated by MAO (250eq.) at $25^{\circ} \mathrm{C}$ under 8 bars of ethylene in toluene after 10 min.

At least two active species are supposed per $\mathrm{Nb}$ precursor: one active in oligomerization and one in polymerization. Indeed, running the catalysis at different precursor concentrations provided different results. At low concentration, HDPE (High Density Poly-Ethylene) is produced with no 1-butene inserted in the polymer backbone, and mostly 1-butene (61 wt $\%)$ was generated in the liquid phase. At higher catalyst concentration, branched LDPE is produced, implying insertion of 1-butene in the polymer backbone. Moreover, selectivity in butenes was significantly lower (down to $9 \%$ in the liquid phase). These results showed the complexity of the mixture upon activation with $\mathrm{EtAlCl}_{2}$ and no conclusion was made in terms of mechanism(s).

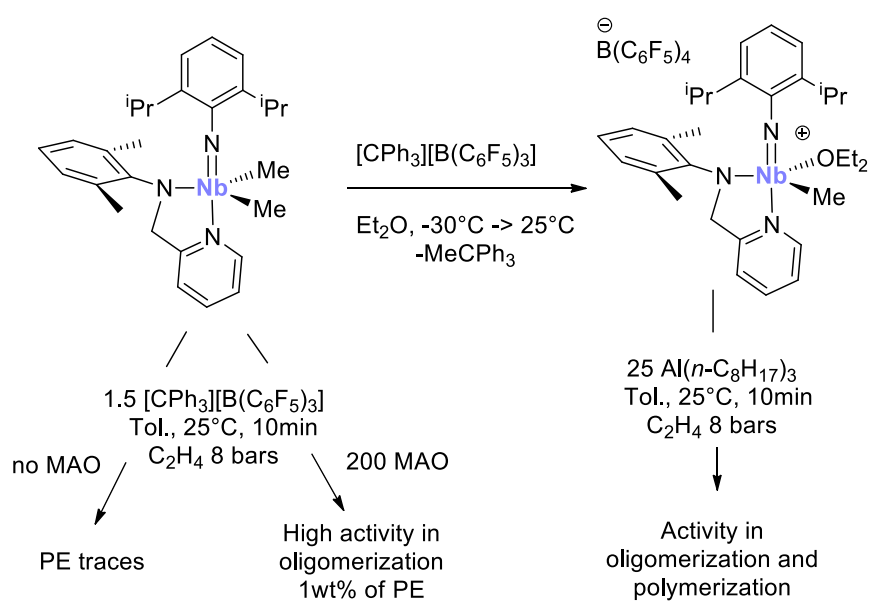

Scheme 22 - Different ways to access $\mathrm{Nb}^{\mathrm{V}}$ cationic active species and results in ethylene in oligomerization.

Also in 2019, Nomura and co-workers reported the synthesis of the niobium analogues of their vanadium catalysts.[57] Different methyl niobium complexes were synthesized and tested in ethylene oligomerization upon activation with MAO (Scheme 21). As with vanadium complexes, dependence with the molar ratio $\mathrm{Nb} / \mathrm{MAO}$ was observed as well as a linear dependence with ethylene pressure for the two bulkier precursors. Comparing with vanadium, a similar active species " $\mathrm{NbMe}^{+,}$" was suggested. 


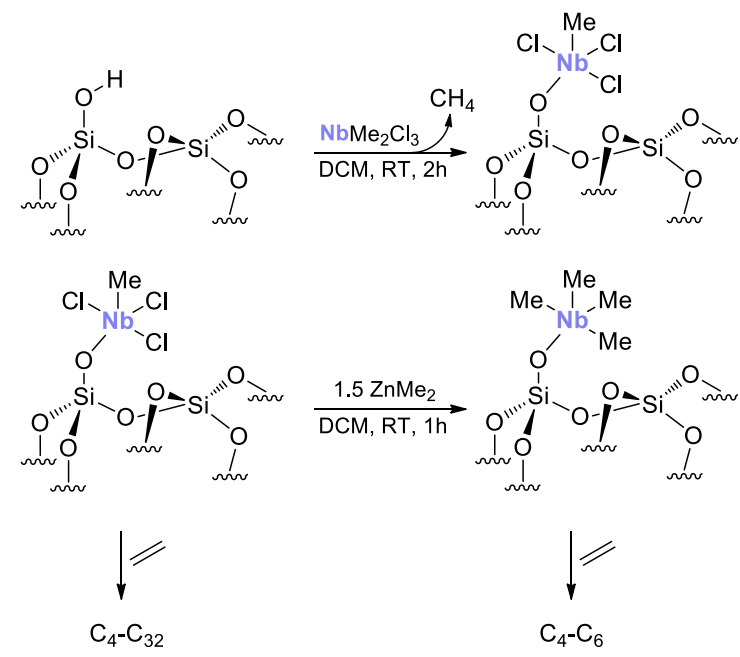

Scheme 23 - Synthesis of two similar grafted niobium complexes, leading to different reactivity in ethylene oligomerization

The neutral dimethyl $\mathrm{Nb}^{\mathrm{V}}$ precursor reacted with 1.5 equivalent of $\left[\mathrm{CPh}_{3}\right]\left[\mathrm{B}\left(\mathrm{C}_{6} \mathrm{~F}_{5}\right)_{4}\right]$ in toluene was not active in ethylene oligomerization/polymerization (Scheme 22, left). The obtained complex was supposed to be inhibited by the coordination of toluene. On the other hand, when MAO was used as an activator, a low activity was observed with $29 \mathrm{wt} \%$ of $\mathrm{PE}$ and $95 \%$ of $\mathrm{C}_{4}$ in the liquid fraction. Using both the trityl borate and MAO as an activating mixture enhanced reactivity in ethylene oligomerization (with similar selectivity) compared to MAO alone (Scheme 22, middle bottom). The cationic monomethyl $\mathrm{Nb}^{\mathrm{V}}-\mathrm{OEt}_{2}$ complex was isolated upon methyl abstraction by trityl (structure determined by NMR). An active catalyst in oligomerization/polymerization was formed by addition of 25 equivalent of $\mathrm{Al}\left(n-\mathrm{C}_{8} \mathrm{H}_{17}\right)_{3}$ (Scheme 22, right). The aluminum compound is proposed to abstract the ether molecule from the niobium center to allow catalysis. XANES studies of dimethyl precursors alone and activated by MAO or $\left[\mathrm{CPh}_{3}\right]\left[\mathrm{B}\left(\mathrm{C}_{6} \mathrm{~F}_{5}\right)_{4}\right]$ showed equivalent spectra, highlighting similar geometry around the niobium centers and similar oxidative state. Following these observations and by comparison with the similar vanadium precursors, a cationic monomethyl $\mathrm{Nb}^{\mathrm{V}}$ was proposed as the first active species. These results are in favor of a Cossee-Arlman mechanism but in this case also, dedicated mechanistic studies (especially using $\mathrm{C}_{2} \mathrm{D}_{4}$ ) to rule out the metallacyclic mechanism have not been reported yet.

In 2017, Basset et al. reported the synthesis of two niobium complexes grafted on a silica surface (Scheme 23), [58] $\mathrm{MeCl}_{3} \mathrm{Nb}^{\mathrm{V}}\left(\mathrm{O}-\mathrm{Si} \equiv\right.$ ) and the tetramethyl derivative $\mathrm{Me}_{4} \mathrm{Nb}^{\mathrm{V}}(\mathrm{O}-\mathrm{Si} \equiv)$ (Scheme 23). Both complexes were fully characterized by solid-state NMR techniques and then tested under ethylene without activator. The first complex was reported to produce olefins from $\mathrm{C}_{4}$ to $\mathrm{C}_{32}\left(76 \%\right.$ of $\left.\mathrm{C}_{4}-\mathrm{C}_{6}\right)$ while $\mathrm{Me}_{4} \mathrm{Nb}^{\mathrm{V}}(\mathrm{O}-\mathrm{Si} \equiv)$ only produced $\mathrm{C}_{4}(91.9 \%)$ and $\mathrm{C}_{6}$. The difference of selectivity is said to be likely due to different coordination sphere and their ability to abstract the $\beta$-hydrogen from the growing chain. It is important to note that in the first case, the percentage of 1-butene in the butene fraction is $83 \%$. In the second case, a 94\% selectivity in 1-butene was observed, highlighting very minor isomerization. The authors proposed a Cossee-Arlman mechanism although mechanistic evidence ruling out a metallacyclic pathway are lacking.

\subsection{Group 6: Chromium, Molybdenum and Tungsten}

\subsubsection{Chromium.}


In a 2019 review, Sydora highlighted the main advances in chromium catalysis for ethylene tri/tetramerization.[59] We will therefore not present the results in details but point out the main conclusions. A large variety of chromium catalysts are known to trimerize ethylene in a selective manner.

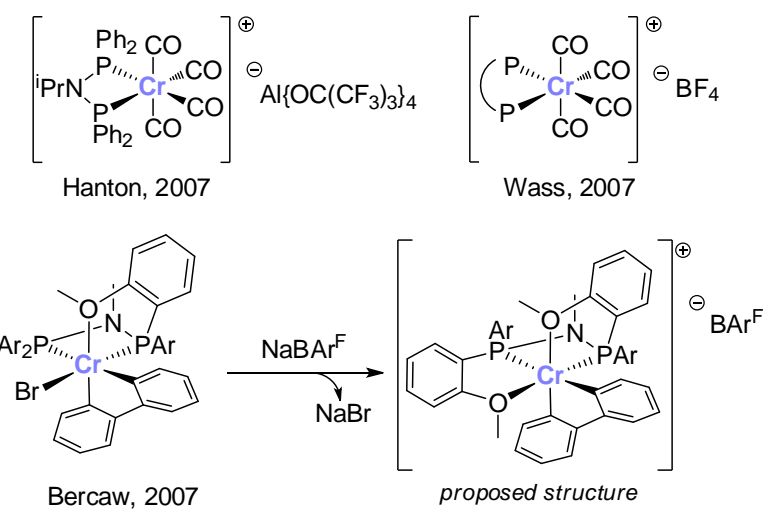

Scheme 24 - Cationic precursors active in ethylene oligomerisation without further activation.

The oxidation state of the species able to perform the oxidative coupling was debated. The synthesis of cationic $\mathrm{Cr}^{\mathrm{I}}$ complexes by Hanton[60] and Wass[61] provided definitive evidence (Scheme 24, top). The cationic $\mathrm{Cr}^{\mathrm{I}}$, without further activation, gave 1-hexene selectively. The same year, a $\mathrm{Cr}^{\mathrm{III}}$ metallacycle was isolated by Bercaw and reported to be active in ethylene trimerization after cationization, supporting the involvement of a metallacycle intermediate (Scheme 24, bottom).[62,63]

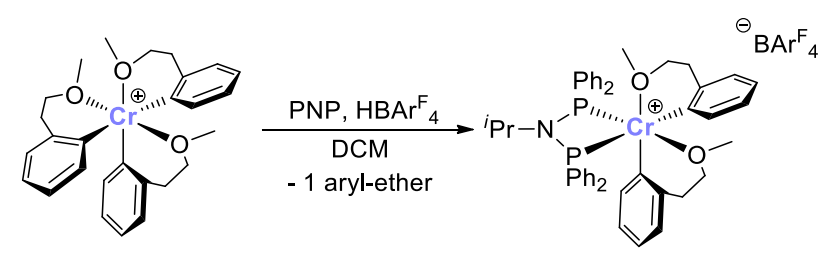

Scheme 25 - Isolated cationic $\mathrm{Cr}^{\mathrm{III}}$ active in ethylene tri- and tetra-merization, without further activation.

Moreover, catalysis performed under a 1:1 mixture of $\mathrm{C}_{2} \mathrm{H}_{4}$ and $\mathrm{C}_{2} \mathrm{D}_{4}$ gave only four isotopologs of 1hexene, in accordance with a metallacycle mechanism, with the cationic system presented in Scheme 24 (bottom).[62] Kinetic studies showed that the coordination of ethylene was reversible until the formation of chromacyclopentane. This complex is too stable to undergo $\beta-\mathrm{H}$ abstraction to form 1-butene, due to ring constraint. Using $\mathrm{CD}_{2} \mathrm{CH}_{2}$, Agapie showed that the formation of chromacycloheptane is irreversible.[63] From there, $\beta-\mathrm{H}$ abstraction and ethylene insertion are competitive. Playing on ligand structure induces one to be favorable over the other. Bulkiness is reported to reduce ethylene coordination/insertion and favor $\beta-\mathrm{H}$ abstraction leading to increased selectivity in 1-hexene.[64] Notably, an isolated bis-aryl-ether cationic $\mathrm{Cr}^{\mathrm{III}}$ species was recently reported to be active in ethylene oligomerization $\left(\mathrm{C}_{6}\right.$ and $\left.\mathrm{C}_{8}\right)$ without further activation (Scheme 25).[65] 


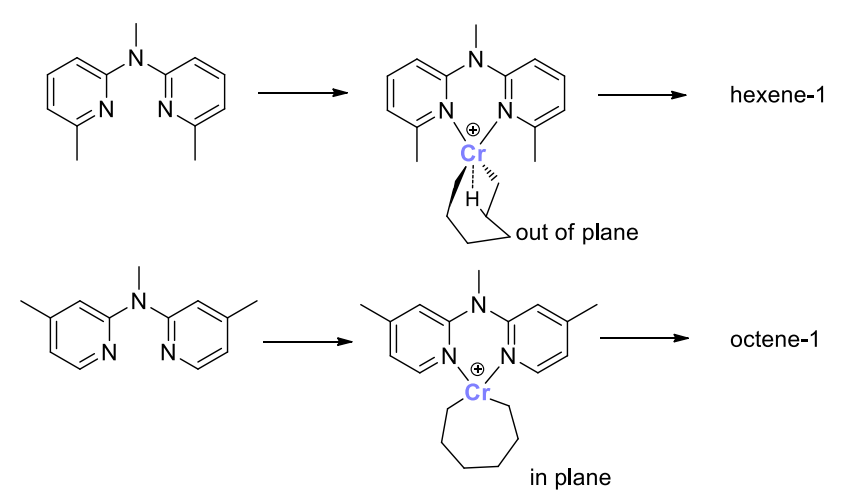

Scheme 26 - Explanation of 1-hexene/1-octene selectivity depending on the methyl position on 2,2'- dipicolylamine ligand.

A recent theoretical study by Liu and coworkers validated the effects of ligand sterics influencing tri- $v s$ tetramerization.[66] The ligand 2,2'- dipicolylamine was chosen for this study (Scheme 26). Two positions of methyl substitution on the ligand were studied as one is reported to selectively produce 1hexene whereas the other leads to 1-octene.[67] When the hindrance is low around chromium, the chromacycloheptane is "in-plane" with the ligand, leading to an unfavored $\beta-\mathrm{H}$ abstraction (TS 4.1 kcal.mol ${ }^{-1}$ higher than TS for ethylene insertion). On the other hand, the methyl in ortho position prohibits the «in-plane » geometry. The "out of plane" chromacycle obtained presents a ring flexibility which allows the $\beta$-H abstraction to occur (TS $11.4 \mathrm{kcal}_{\mathrm{mol}}{ }^{-1}$ lower than TS for ethylene insertion).

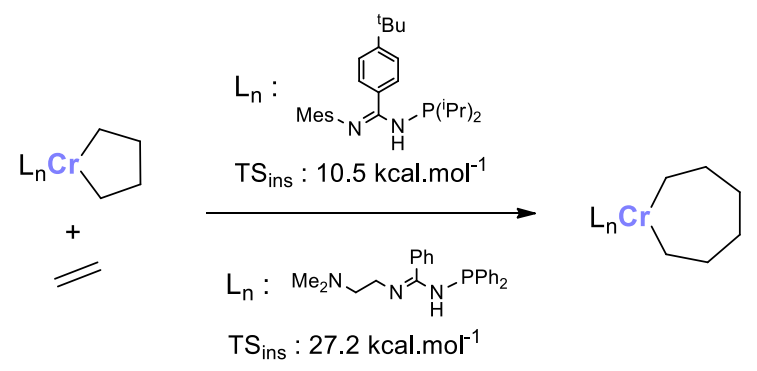

Scheme 27 - Energy comparison for ethylene insertion into chromacyclopentane depending of ligand hapticity.

In order to understand why $(\mathrm{P}, \mathrm{N})$ ligands induce much more activity than tridentate ligands, Ess, Bischof and coworkers carried out a DFT studies.[68] They compared the energies of the different intermediates in the metallacyclic mechanism and observed that in the case of tridentate ligand, the metallacyclopentane was the resting state. It implied a high energy transition state for the insertion of a new ethylene in the metallacycle (Scheme 27).

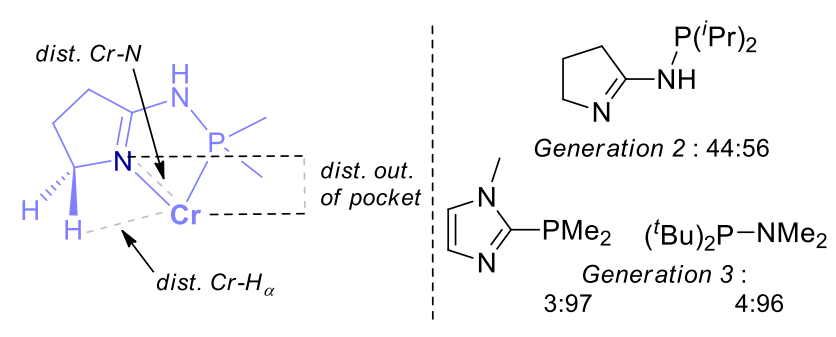

Scheme 28 -Left: parameters influencing 1-octene selectivity. Right: comparison between an existing generation 2 and proposed generation $3(\mathrm{P}, \mathrm{N})$ ligands. Selectivity is given as 1-hexene:1-octene.

A new method to reach high selectivity in 1-octene was subsequently proposed by Ess, Bischof and coworkers using DFT calculation combined with machine learning on $\mathrm{Cr} /(\mathrm{P}, \mathrm{N})$ ligand systems.[69] By studying the impact of different parameters on the selectivity, they were able to define $\mathrm{Cr}-\mathrm{N}$ and $\mathrm{Cr}-\mathrm{H}_{\alpha}$ 
distances and the distance out of pocket of the ligand as being the most important to increase 1-octene selectivity (Scheme 28, left). From there, they proposed a $(\mathrm{P}, \mathrm{N})$ ligand with PCN or PN linkages that should lead to a $\geq 95 \%$ selectivity in 1-octene (generation 3 compared to generation 2, Scheme 28, right). Although the method is able to reproduce selectivity with known $\mathrm{Cr} /(\mathrm{P}, \mathrm{N})$ ligand systems, these predictive results have yet to be confirmed experimentally.

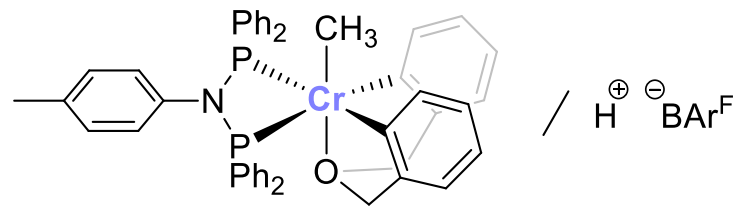

Scheme 29 - Cr ${ }^{\mathrm{III}}$ system studied by Agapie et al.

Although $\mathrm{Cr}^{\mathrm{I}} / \mathrm{Cr}^{\mathrm{III}}$ cycle seems to be most likely to perform trimerization of ethylene, doubts still remain when studies are made on non-isolated systems. For example, Brückner \& Bauer's teams supports a Cr ${ }^{\text {II }}$ complex as the active species in the $\mathrm{Cr}(\mathrm{acac})_{3} / \mathrm{PNP} / \mathrm{MMAO}$ thanks to EPR, XANES and EXAFS studies.[70] When using $\mathrm{AlEt}_{3}, \mathrm{Al}^{\mathrm{i}} \mathrm{Bu}_{3}$ and $\mathrm{AlOct}_{3}$ as co-catalyst, $\mathrm{Cr}^{\mathrm{I}}$ is detected at a 15 to $30 \%$ ratio (compared to other generated $\mathrm{Cr}$ oxidation states) but the different mixtures were twice less active than system with MMAO (2\% of $\mathrm{Cr}^{\mathrm{I}}$ detected). The EXAFS and XANES studies suggested the presence of a $\mathrm{Cr}^{\mathrm{II}}$ species for this system. Similarly, Agapie and co-workers made a Pulse EPR analysis (HYSCORE \& ENDOR) on a cationic $\mathrm{Cr}^{\text {III }}$ system (Scheme 29).[71] After addition of ethylene (100eq.) on that complex, a $\mathrm{Cr}^{\mathrm{I}}$ species was detected (not fully characterized) among others. However, when isolated, this $\mathrm{Cr}^{\mathrm{I}}$ complex was poorly active in ethylene trimerization ( 8 eq. of 1-hexene formed) compared to the initial system in the same conditions (>1100 gram of hexene produced per gram of $\mathrm{Cr}$ ).[72]

Recently, Tromp used Cr K-Edge XAS and EPR experiments combined with DFT calculations to propose $\mathrm{Cr}^{\mathrm{II}}$ species as the active species in the trimerization of ethylene.[73,74] Square planar $\mathrm{Cr}^{\mathrm{II}}$ complexes were observed after activation with MMAO (400eq.) in two different cases (Scheme 30). DFT calculation rationalized nicely their reactivity in ethylene oligomerization via the metallacyclic pathway, supporting a $\mathrm{Cr}^{\mathrm{II}} / \mathrm{Cr}^{\mathrm{IV}}$ cycle.

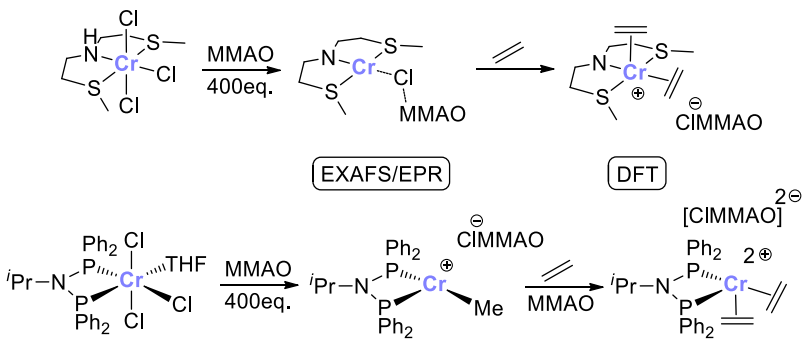

Scheme 30 - Proposed activation of $\mathrm{Cr}^{\mathrm{III}}$ pre-catalysts with MMAO and their reactivity with ethylene.

These studies by Agapie, Brückner and Tromp do highlight the difficulty to determine the active species in such systems and stimulate/entertain the debate on the oxidation state required for catalysis.

\subsubsection{Tungsten}

A variety of imido tungsten catalysts were reported to selectively dimerize ethylene to 1-butene. However, as highlighted in a 2015 review,[75] very few mechanistic studies have been reported. In 1999, Olivier-Bourbigou and Gérot reported the synthesis of the phenylimido $\mathrm{W}^{\mathrm{IV}}$ complex $\left[\left(\mathrm{PMe}_{3}\right)_{3} \mathrm{~W}(\mathrm{NPh}) \mathrm{Cl}_{2}\right]$.[76] When activated by 4.5 eq. of $\mathrm{AlCl}_{3}$, the generated complex is active in 
ethylene oligomerization ( $80 \%$ of butenes, $18 \%$ of hexenes). A metallacyclic pathway is proposed after the abstraction of a phosphine ligand and coordination of ethylene (Scheme 31, top). The passage by a metallacycle was supported by DFT calculations for mono-imido tungsten precursors[77] and extrapolated to bis-imido tungsten.[78] It is important to notice that the metallacycle is only reachable with the presence of the aluminum co-catalyst present in the coordination sphere of tungsten (Scheme 31, bottom).

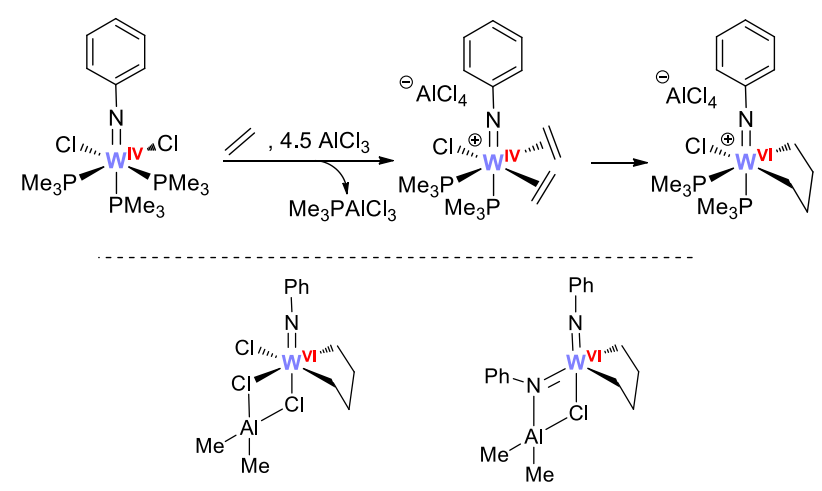

Scheme 31 -Top: Proposed mechanisms for the generation of a $\mathrm{W}^{\mathrm{VI}}$ metallacyclopentane. Bottom: metallacycle intermediate proposed by Tobish.

A 2010 study by Hanton and co-workers reported a catalytic system $\left(\mathrm{WCl}_{6} / 2 \mathrm{PhNH}_{2} / 4 \mathrm{NEt}_{3} / 12 \mathrm{EADC}\right)$ able to dimerize 1-pentene into a mixture of $\mathrm{C}_{10}$ isomers. The analysis of these $\mathrm{C}_{10}$ isomers suggested the formation of several active species able to follow both metallacyclic and Cossee-Arlman mechanism.[79] Moreover, the catalytic system was reported not to isomerize alkenes. Nevertheless, when putting the activated catalyst under an atmosphere of $\mathrm{C}_{2} \mathrm{D}_{4} / \mathrm{C}_{2} \mathrm{H}_{4}(1 / 1)$, hydrogen scrambling is observed, consistent with a Cossee-Arlman mechanism.
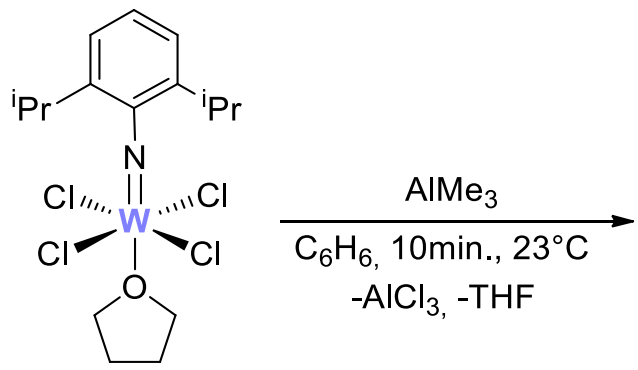<smiles>CCCc1cccc(CCC)c1N=[W](C)(C)Cl</smiles>

Scheme 32 - Generation of the $\mathrm{W}^{\mathrm{VI}}$ active species.

In 2016, O'Hare and coworkers reported the synthesis of a trimethyl $\mathrm{W}^{\mathrm{VI}}$ mono-imido complex (Scheme 32).[80] This precursor is reported to oligomerize ethylene. The authors reported that the lower the Al/W ratio is, the higher the selectivity in 1-butene (for similar TONs)-is, suggesting a metallacyclic pathway. With higher Al/W ratio ( ${ }^{1} \mathrm{H}$ NMR study with $5 / 1$ ratio), slight decomposition results in increased isomerization into 2-butene.

In 2018, Dyer and co-workers provided some insights into the mechanism followed by mono and bisimido $\mathrm{W}^{\mathrm{VI}}$ precursors after activation. In the case of mono-imido derivatives, the authors isolated a polymetallic $\mathrm{W}^{\mathrm{V}}$ complex after activation of $(\operatorname{dippN}) \mathrm{W}^{\mathrm{VI}} \mathrm{Cl}_{4}(\mathrm{THF})$ with $\mathrm{MeAlCl}_{2}$ (Scheme 33).[81] Moreover, by comparison of a series of $\mathrm{W}^{\mathrm{IV}}, \mathrm{W}^{\mathrm{V}}$ and $\mathrm{W}^{\mathrm{IV}}$ complexes, they assessed that $\mathrm{W}^{\mathrm{V}}$ is the most probable catalytic active species. 


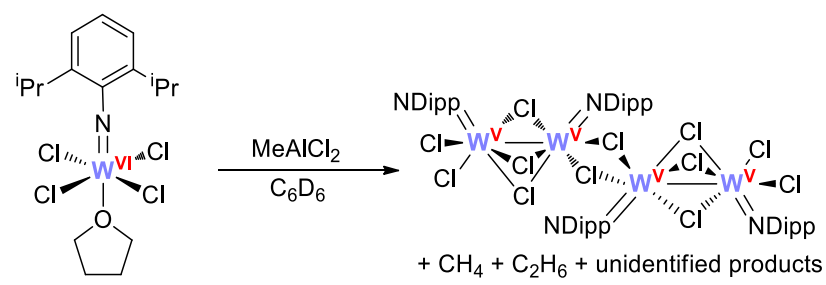

Scheme 33 - Generation of a $\mathrm{W}^{\mathrm{V}}$ tetra-metallic cluster after activation of a mono-imido $\mathrm{W}^{\mathrm{VI}}$ precursor.

The active $\mathrm{W}^{\mathrm{V}}$ species can be accessed by comproportionation of $\mathrm{W}^{\mathrm{IV}}$ and $\mathrm{W}^{\mathrm{VI}}$ as well as by activation of $\mathrm{W}^{\mathrm{VI}}$ complexes with alkyl aluminum. The authors suggested as well that the alkyl aluminium derivative was of great importance in the mechanism as $\mathrm{MeAlCl}_{2}$ and $\mathrm{EtAlCl}_{2}$ gave different selectivity when used as co-catalyst of $(\operatorname{dippN}) \mathrm{W}^{\mathrm{VI}} \mathrm{Cl}_{4}(\mathrm{THF})$. These observations support a W/Al active species. They also evidenced that the formation of hexenes is due to selective co-dimerization of butene and ethylene (absence of linear hexenes).

In the case of the (bis-imido) $\mathrm{W}^{\mathrm{VI}}$ derivatives, similar activities (up to $409410 \mathrm{~mol}_{\mathrm{C} 2 \mathrm{H} 4} \cdot \mathrm{mol}_{\mathrm{W}}{ }^{-1} \mathrm{~h}^{-1}$ ) and selectivity are reported for the formation of butenes (up to $79.6 \mathrm{wt} \%$, and $82.4 \%$ 1-butene) and hexenes.[82] In order to question the metallacyclic mechanism involving the generation of an unsaturated (bis-imido) $\mathrm{W}^{\mathrm{IV}}$ intermediate, they synthesized the (bis-imido) $\mathrm{W}^{\mathrm{IV}}\left(\mathrm{PMe}_{3}\right)_{3}$ as its potential precursor upon activation. They observed a low activity of the (bis-imido) $\mathrm{W}^{\mathrm{IV}}\left(\mathrm{PMe}_{3}\right)_{3}$ precursor when activated by EtAlCl${ }_{2}$ and an even lower activity when activated by $\mathrm{AlCl}_{3}$ (Scheme 34), revealing that the mechanism for ethylene dimerization is more complicated than the proposed metallacyclic pathway alone. The authors suggested the pivotal role of alkylaluminium species that need however to be investigated.

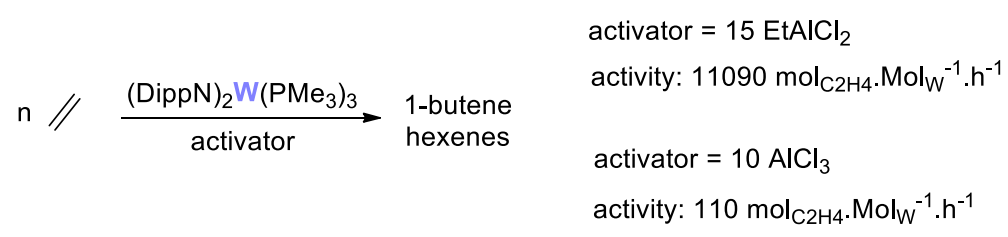

Scheme 34 - Influence of co-catalyst on a bis-imido $\mathrm{W}^{\mathrm{IV}}$ precursor.

Despite these insights pertaining to the active complexes, the precise mechanism is still unclear both for mono- and bis-imido complexes.

\subsubsection{Molybdenum}

Bis-imido molybdenum $(\mathrm{ArN})_{2} \mathrm{Mo}\left(\mathrm{NH}^{\mathrm{t}} \mathrm{Bu}\right)_{2}$ and $(\mathrm{ArN})_{2} \mathrm{MoCl}_{2}(\mathrm{DME})$ complexes have been synthesized by Dyers and co-workers (Scheme 35), and their reactivity tested in ethylene oligomerization (40 bar) upon activation with $\mathrm{MeAlCl}_{2}$ or $\mathrm{EtAlCl}_{2}$ (15 equivalents). Moderate selectivity into butenes (88.9 to $97.5 \%$ ) and 1-butene (63.7 to 78.6 in the butenes fraction) was observed as well as hexenes $(8.4-9.8 \%$ in the liquid fraction), octenes (0.1-2.4\% in liquid fraction) and $\mathrm{PE}(0.1$ to $0.5 \%)$ after $1 \mathrm{~h}$ at $60^{\circ} \mathrm{C}$ in $\mathrm{PhCl}$ (activity: from 27 to $64 \mathrm{kmol}$ of ethylene per mol of Mo complex per hour). 


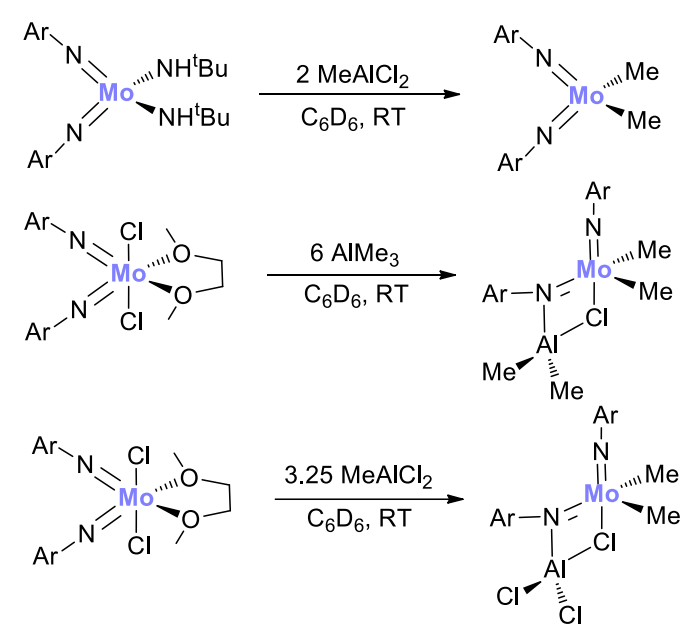

Scheme 35 - Synthesis of different dimethyl Mo complex. Ar=Dipp.

The authors made efforts to characterize the active species. The (bis-imido) dimethyl Mo complex was synthesized (Scheme 35, top). The addition of 6 equivalents of $\mathrm{AlMe}_{3}$ or 3.25 equivalents of $\mathrm{MeAlCl}_{2}$ to $(\mathrm{ArN})_{2} \mathrm{MoCl}_{2}$ (DME) yielded bimetallic $\mathrm{Mo} / \mathrm{Al}$ complexes (Scheme 35, middle and bottom). Under low pressure of ethylene (5 equivalents), these two heterobimetallic and the monometallic complexes did not oligomerize ethylene. The reaction of these complexes has not been reported under higher ethylene pressures used in catalysis, which precludes definitive conclusion on the active species.

In contrast with these results, some molybdenum complexes have been reported to follow a metallacyclic pathway. This reactivity will be discussed in the next section.

\subsection{Nickel.}

Nickel complexes are very well known to follow a Cossee-Arlman mechanism. Despite this fact, researchers have studied the possibility for nickel fragment to reach a metallacycle after oxidative coupling of the ethylenic molecules.

In 1970, a fluorinated nickellacyclopentane was synthesized from the reaction between a nickel(0) complex and tetrafluoro-ethylene (TFE).[83] The formation of per-fluorocyclobutane or per-fluoro-1butene was not observed.[84] 45 years later, in 2015, the synthesis of a mixed metallacycle (ethylene/TFE) was reported by reacting $\mathrm{PPh}_{3}$ and ethylene with $\mathrm{Ni}(\mathrm{COD})_{2}$ followed by the addition of TFE (Scheme 36, top).[85] Likewise, the formation of butene or cyclobutane derivatives was not observed from the metallacycle. However, when the mixed metallacycle was further reacted with ethylene, 5,5',6,6'-tetrafluoro-1-hexene was obtained quantitatively. After careful optimization, Ogoshi and co-workers, managed to reach a maximum TON of 13 of 5,5',6,6'-tetrafluoro-1-hexene when using a bulkier and more electron-donating phosphine $\left(\mathrm{PCy}_{3}\right)$ as well as an excess of ethylene over TFE. Mechanistically, the intermediacy of a mixed metallacycle followed by $\beta-\mathrm{H}$ transfer is supported by the formation of the terminal difluoromethyl moiety (Scheme 36, bottom). It is the first example of cooligomerization of ethylene with a nickel complex going through a metallacycle. Like Binger, Ogoshi did not observe the formation of a nickelacyclopentane from ethylene alone.

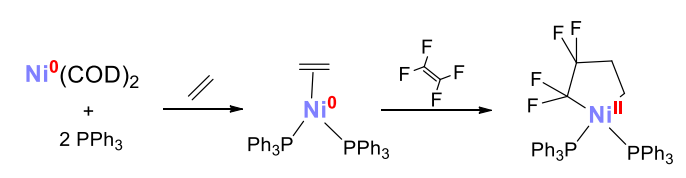




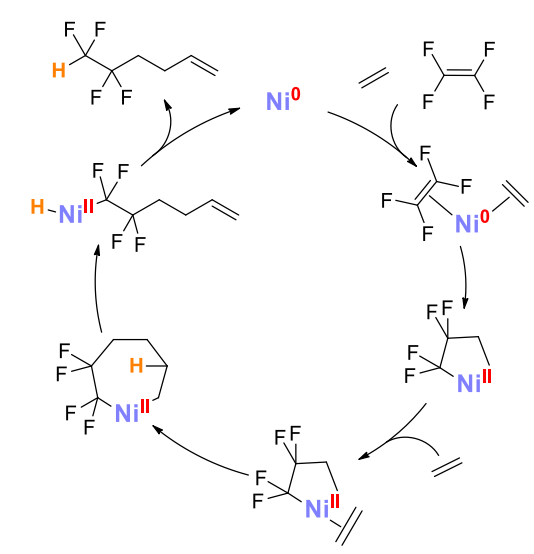

Scheme 36 - Formation of metallacycle from a Ni0 complex and TFE. Proposed catalytic mechanism for the formation of tetrafluoro-1-hexene.

A DFT investigation reported by Bernardi and coworkers in 1998 supported Binger and Ogoshi observations, using $\mathrm{PH}_{3}$ as model phosphine.[86] The energy (TS) to reach a metallacycle from the

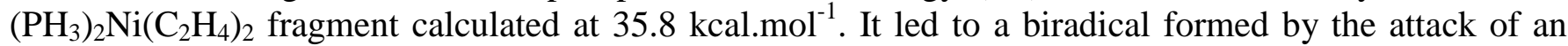
additional ethylene molecule (Scheme 37). The direct oxidative coupling pathway was not found.

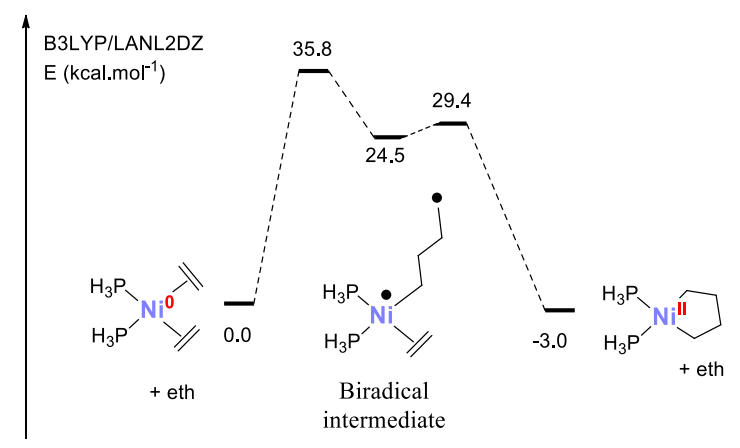

Scheme 37 - Theoretical study on the obtention of metallacyclopentane from $\left(\mathrm{PH}_{3}\right)_{2} \mathrm{Ni}_{(}\left(\mathrm{C}_{2} \mathrm{H}_{4}\right)_{2}$ fragment.

These results contrast from earlier reports by Grubbs on the reactivity of nickellacyclopentanes. Starting from bis halogeno nickel (II) complexes, the formation of metallacycles was achieved upon addition of dilithiobutane (characterized by NMR and EA). The complexes were stable under $10^{\circ} \mathrm{C}$. While studying the controlled evolution of the different metallacycles (to form ethylene, 1-butene or cyclobutane), Grubbs observed that the final product depended on the amount of phosphine in the reaction medium. When an excess of phosphine is added, ethylene is obtained as the major product, while in the presence of two phosphines, cyclobutane is observed as the major product.[87] Finally, when only one ligand is coordinated on the nickel center, only 1-butene is observed (Scheme 38, top).[88]

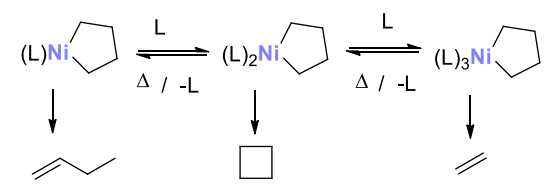




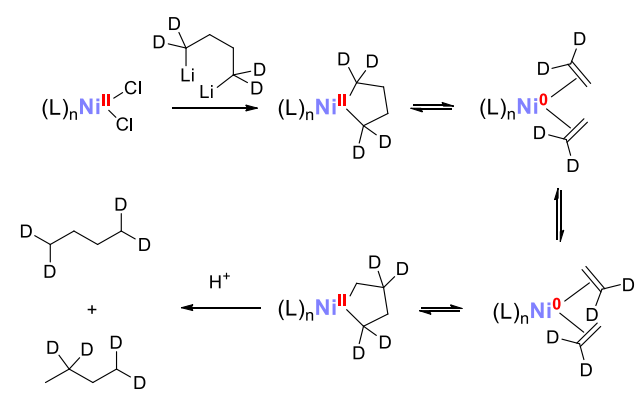

Scheme 38 - Grubbs experiment showing the existence of a nickellacyclopentane.

In another study, Grubbs and Miyashita used 1,1,4,4-tetradeuterated 1,1-dilithiobutane and showed an equilibrium between nickel bis-ethylene and nickelacyclopentane complexes (Scheme 38, bottom).[89] In the presence of an excess of phosphine, ethylene is displaced. With less ligand, the nickel is more electrophilic which could induce $\beta-\mathrm{H}$ transfer and 1-butene formation. In a fourth study, Grubbs reported the formation of 1-butene while putting $\left(\mathrm{PPh}_{3}\right)_{3} \mathrm{Ni}\left(\mathrm{CH}_{2}\right)_{4}$ under ethylene at $80^{\circ} \mathrm{C}$.[90] In this case, dissociation of two phosphines was proposed. At room temperature, cyclobutane was observed, pointing the decoordination of only one phosphine (Scheme 38). Finally, the catalytic synthesis of 1-butene from ethylene via nickelacyclopentane, although with a low TON $(23,19 \mathrm{~h})$ was proposed.[90]

\begin{tabular}{cc}
\hline Oxidation state & $\triangle E\left(\mathrm{kcal}^{\mathrm{mol}}{ }^{-1}\right)$ \\
\hline $\mathrm{Ni}^{0} / \mathrm{Ni}$ & 50.4 \\
$\mathrm{Ni}^{1} / \mathrm{Ni}$ & 38.7 \\
$\mathrm{Ni}^{\mathrm{III}} / \mathrm{Ni}^{\mathrm{IV}}$ & 20.0 \\
\hline
\end{tabular}

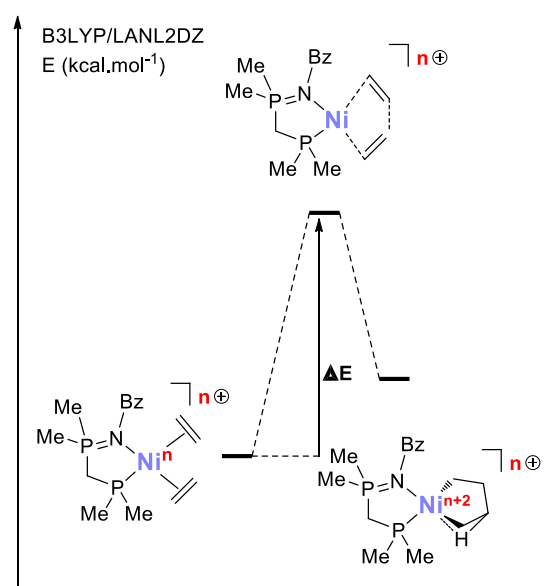

Scheme 39 - Determination of the most probable oxidation state for nickel to realize oxidative coupling with two ethylene.

In conclusion, there is an apparent discrepancy between results obtained under similar conditions. As presented above, both Ogoshi and coworkers,[85] and Olivier-Bourbigou, Breuil and coworkers[91] did not observe the formation of cyclobutane or 1-butene while using the $\left(\mathrm{PPh}_{3}\right)_{2} \mathrm{Ni}\left(\mathrm{C}_{2} \mathrm{H}_{4}\right)$ and $\left(\mathrm{PCy}_{3}\right) \mathrm{Ni}\left(\mathrm{C}_{2} \mathrm{H}_{4}\right)_{2}$ complexes.

Several nickel (II) precursors were reported to selectively dimerize ethylene into butenes after activation.[92-95] Le Floch, Adamo and co-workers carried out a DFT study on their catalytic system using P,N bidentate ligands[95] to compare Cossee-Arlman and metallacyclic mechanism.[96] Because the exact nature of the catalytically active complex was not known because of activation by excess MAO under ethylene, these authors evaluated the reactivity at the Ni center at different oxidation states. Thus, the oxidative coupling of two ethylene molecules on $[(\mathrm{P}, \mathrm{N}) \mathrm{Ni}]^{\mathrm{n}+}$ fragments (with $\mathrm{n}=0,1,2$ ) was shown to be facile (TS: $\left.20.0 \mathrm{kcal}^{\mathrm{mol}}{ }^{-1}\right)$ in the case of a dicationic nickel(II) fragment $\left[(\mathrm{P}, \mathrm{N}) \mathrm{Ni}\left(\mathrm{C}_{2} \mathrm{H}_{4}\right)_{2}\right]^{2+}$, while it was highly demanding/unfeasible at $\mathrm{Ni}^{+}$and $\mathrm{Ni}^{(0)}$ (38.7 and $50.4 \mathrm{kcal}^{-\mathrm{mol}^{-1}}$ resp.) (Scheme 39). 
Starting from the kinetically accessible metallacycle, they compared the formation of 1-butene and metallacycle expansion via insertion of ethylene. The difference in energy between the two transition states is of $11.6 \mathrm{kcal}_{\mathrm{mol}}{ }^{-1}$ in favor of $\beta-\mathrm{H}$ transfer. These calculations nicely rationalized the high selectivity for butene (97.7\%) they reported in 2007 using $(\mathrm{P}, \mathrm{N}) \mathrm{NiBr}_{2}$ precursors activated with MAO. It is to be noted that these authors also envisaged the Cossee-Arlman mechanism from a postulated $\left[(\mathrm{P}, \mathrm{N}) \mathrm{Ni}(\mathrm{H})\left(\mathrm{C}_{2} \mathrm{H}_{4}\right)\right]^{+}$complex. The energy requirements to form 1-butene is lower by $5.6 \mathrm{kcal}^{-\mathrm{mol}^{-1}}$ compared to the energy required for the insertion of a new ethylene molecule in the nickel-carbon bond of the $\left[(\mathrm{P}, \mathrm{N}) \mathrm{Ni}\left(\mathrm{C}_{4} \mathrm{H}_{7}\right)\right]^{+}$complex. Thus, calculations predict that the energetic requirements of both the Cossee-Arlman $\left(\mathrm{Ni}^{\mathrm{II+}}\right)$ and metallacyclic $\left(\mathrm{Ni}^{\mathrm{II+}} / \mathrm{Ni}^{\mathrm{IV}+}\right)$ mechanisms are compatible with high selectivity in 1-butene formation with the $(\mathrm{P}, \mathrm{N})$ ligand system.

\section{From ethylene to cycloalkane/butadiene}

1-alkenes are not the only possible products obtained from metallacyclopentane intermediates. In this section will be discussed the formation of metallacycles and their evolution to cyclobutane or butadiene derivatives.

\subsection{From ethylene to cycloalkane}

\subsubsection{Iron}

In 2006, Chirik and coworkers reported the [2+2] cyclo-addition of non-conjugated dienes thanks to a formally $\mathrm{Fe}^{0}$ complex, supported by a redox active ligand PDI (PDI = pyridine diimine, Scheme 40), in the synthesis of different bicyclo[0.2.3]heptane.[97] A metallacyclopentane was proposed as the intermediate before a C-C reductive elimination occurred to form the cyclobutane derivatives. In 2013, after ligand structure and diene variation, Chirik and co-workers reported the isolation of a metallacycle intermediate (Scheme 40), supporting their mechanistic hypothesis.[98]

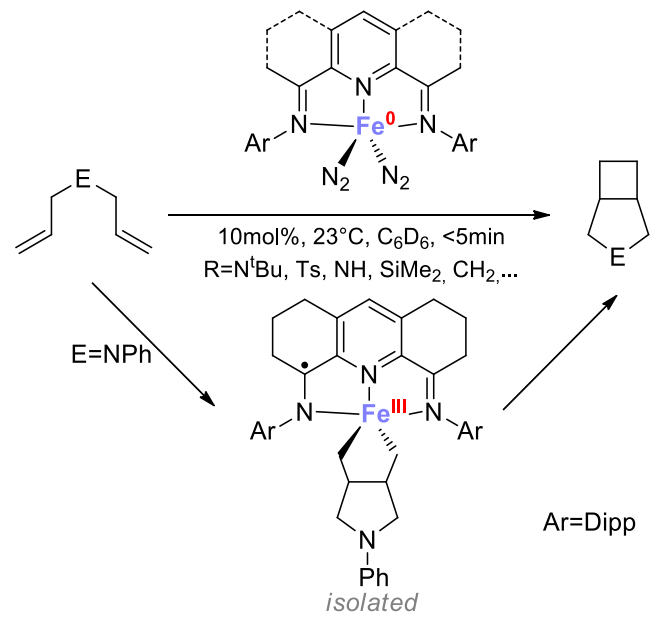

Scheme 40 - Cyclomerization of dienes and isolation of a metallacycle.

Facing difficulties to promote the [2+2] cycloaddition with non-activated alkenes due to $\mathrm{C}-\mathrm{H}$ activation of the ${ }^{i} \operatorname{Pr}$ group of Dipp, the synthesis of a similar PDI ligand with cyclopentyl instead of ${ }^{\mathrm{i}} \mathrm{Pr}$ groups was reported to cyclodimerize a large scope of terminal alkenes such as propene and 1-hexene.[99] Based on their previous work, oxidative coupling of two alkenes is proposed to yield a metallacycle prior to C-C coupling and cyclobutane formation. When steric properties of the PDI ligand are small, a mixture of 2,3dimethylbutene and trans-1,2-dimethylcyclobutane is observed, showing a competition between reductive 
elimination and $\beta-\mathrm{H}$ transfer (Scheme 41). Notably, these results represent the first example for an iron complex to dimerize propylene following a metallacyclic pathway.
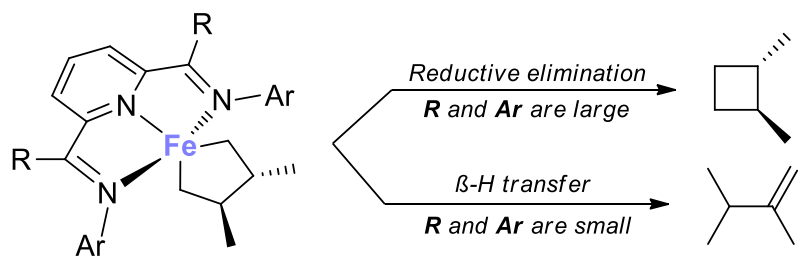

Scheme 41 - Competition between C-C coupling and $\beta-H$ transfer, depending on ligand steric.

Chen and $\mathrm{Hu}$ determined the role of the redox active PDI ligand using a combined CASPT2/DFT approach.[100] Comparing the reductive elimination using electronically different iron metallacycle, they showed that the metallacycle intermediate possessed an open-shell diradicaloid state in which one electron resides on the ligand with an antiferromagnetic coupling between PDI ${ }^{-}$and the low-spin $(\mathrm{S}=1 / 2)$ $\mathrm{Fe}^{(\mathrm{III})}$ center. From there, a transition state located at $24.4 \mathrm{kcal}^{\mathrm{mol}}{ }^{-1}$ was determined to form dimethylcyclobutane in accordance with the experimental results (reaction ran at $100^{\circ} \mathrm{C}$ ).

In 2020, Chirik and co-workers carried out a comparative study between [2+2] cycloadditions of different unactivated alkene: 1-octene and 1,7-octadiene.[101] 1-octene is reported to be dimerized to trans-substituted-cyclobutane by the iron complex whereas the diene formed cis-cyclobutane. These results are supported by kinetic and DFT studies and analysis of the different resting states. When using 1-octene, the resting state is determined to be (PDI)Fe( $\left.\mathrm{N}_{2}\right)\left(1\right.$-octene) thanks to freeze-quench ${ }^{57} \mathrm{Fe}$ Mössbauer spectroscopy. To enter the catalytic cycle, the decoordination of $\mathrm{N}_{2}$ has to occur before the coordination of a second 1-octene (Scheme 42). This step is the limiting step of the catalytic cycle, supported by kinetic studies (-1 order dependence with $\mathrm{N}_{2}$ pressure). In the case of diene, the resting state is reported to be the metallacycle with hydrogens in trans-position (X-ray structure), despite the fact that the major product is the cyclobutane with cis hydrogens $(92 \%)$.
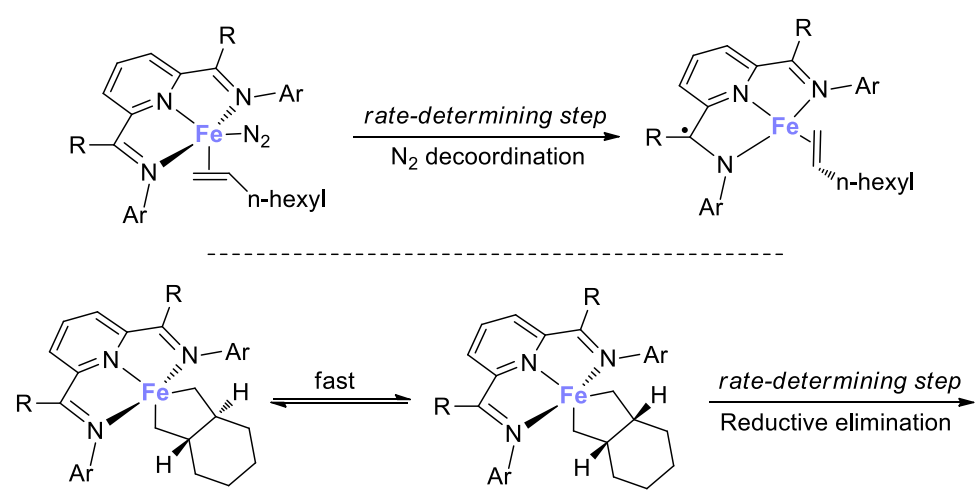

Scheme 42 - Different resting state depending of the substrate (1-octene or 1,7 octadiene).

DFT calculations supported that the two metallacyclic isomers lie very close in energy. Moreover, the transition state from the "cis-metallacycle" to form the cyclobutane is located at a lower energy compared to the transition state from the "trans-metallacycle". KIE ${ }^{13} \mathrm{C} /{ }^{12} \mathrm{C}$ kinetic studies show that there was a fast exchange between the cis and trans metallacycle followed by an irreversible reductive elimination (Scheme 42).

\subsubsection{Cobalt}


Chirik's group extended the use of bis(imino)pyridine to cobalt and reported in 2010 the synthesis of a $\mathrm{Co}^{\mathrm{I}}$ dinitrogen complex.[102] In 2015, they showed that the cobalt catalyst was able to coordinate dienes (the $\mathrm{Co}^{\mathrm{I}}$ diene complex is reported to be the resting state) and to form cyclobutane derivates ( $1 \mathrm{~mol} \%$ of Co).[103] A comparison with iron catalysts showed that cobalt was less active for the cyclisation reaction. As for iron, the reductive elimination is preferred when the aromatic of the ligand is bulky. Moreover, a deuterium labelling study showed that the Z-protons of the terminal alkene of the diene did end up in cis position in the cyclobutane products (Scheme 43).

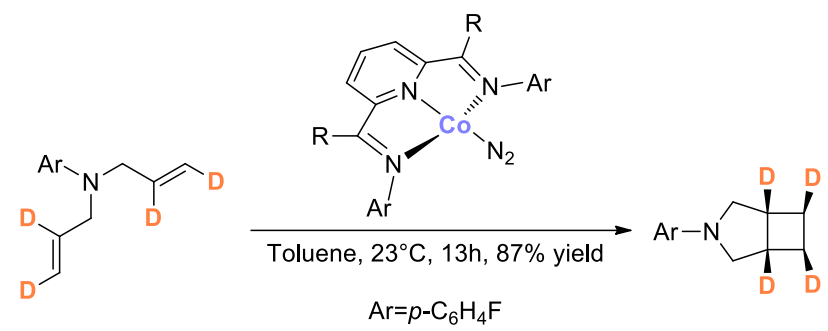

Scheme 43 - Labelling study for the cyclomerization of diene with cobalt bis(imino)pyridine complex.

\subsubsection{Nickel.}

As previously mentioned, it is well known that nickel complexes can oligomerize ethylene via a CosseeArlman mechanism. Notwithstanding this observation, some nickel fragments are able to promote the oxidative coupling between two alkenes. For example, Binger and co-workers discovered as early as 1974 that reacting $\mathrm{Ni}(\mathrm{COD})_{2}$ with strained olefins (3,3'-dimethylcyclopropene or norbornene) resulted in the formation cyclobutane derivates.[104] They later used (bipy)Ni(COD) to isolate the first nickelalacyclopentane in 1976 (Scheme 44, top).[105,106] The isolated complex, upon dissolution, yielded the cyclobutane derivates. Here, as in the case of iron, a reductive elimination occurred at the metallacycle stage. The hydrogen atoms at the $\beta$-position are located too far from the nickel center to allow $\beta-\mathrm{H}$ transfer to form the alkene. In comparison, the synthesis of the metallacycle (bipy) Ni $\left(\mathrm{CH}_{2}\right)_{4}$ from $\mathrm{Ni}(\mathrm{COD})_{2}, 4$ bipyridine and dibromo-butane was reported by Binger in 1979.[107] They showed that at $165^{\circ} \mathrm{C}$ the major decomposition product was 1-butene (73.6\%, Scheme 44, bottom). However, neither (Bipy)Ni(COD) nor $\mathrm{Ni}(\mathrm{COD})_{2}$ were reported to react under ethylene to form the metallacyclopentane.

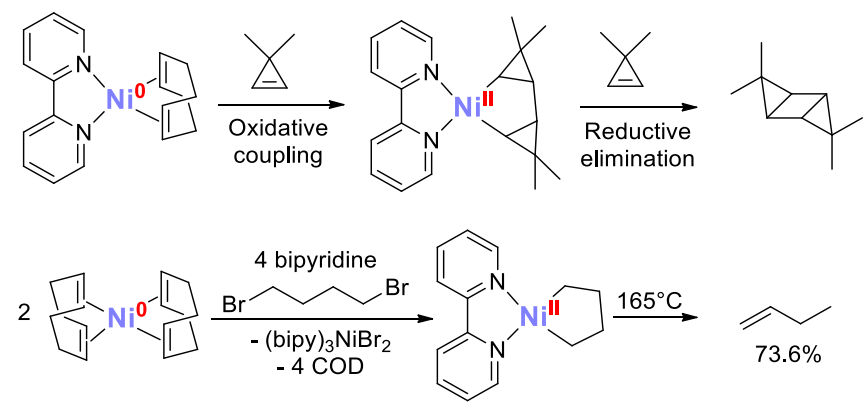

Scheme 44 - top: Synthesis of a cyclobutane derivate from a bipyridine nickel(0) complex and the constrained olefin dimethylcyclopropene. Bottom: Synthesis of bipyridine nickelacyclopentane and its decomposition study.

\subsection{From ethylene to butadiene}

\subsubsection{Iridium}

Oxidative coupling of two ethylene molecules has been reported once for $\mathrm{d}^{9}$ transition metals, in 2018 , by Goldman and coworkers.[108] They reported the synthesis of an iridium complex able to catalyze both dimerization of ethylene (at low pressure, 2 bar) and dehydrogenative coupling of ethylene to form 
butadiene and ethane (at higher pressure, $8-12$ bar) at $100^{\circ} \mathrm{C}$. After $\mathrm{CO}$ addition, they were able to isolate two complexes, including an iridacyclopentane, showing that oxidative coupling occurred in the mechanism leading to butadiene. The formation of an $\mathrm{Ir}-\mathrm{H}$ bond after the $\beta-\mathrm{H}$ elimination from the metallacyclopentane followed by the insertion of ethylene in the Ir-H bond is proposed to explain the formation of butadiene. DFT calculation supported this hypothesis. Indeed, formation of the metallacyclopentane is reported as the determining step $\left(27.2 \mathrm{kcal}_{\mathrm{mol}}{ }^{-1}\right)$ and is followed by the $\beta-\mathrm{H}$ elimination. From this step, the most favorable pathway involves ligand partial decoordination allowing the insertion of ethylene in the Ir-H bond. Butadiene and the $\left[\mathrm{L}_{n} \mathrm{IrHEt}\right]$ complex are then formed via $\beta-\mathrm{H}$ elimination (Scheme 45).

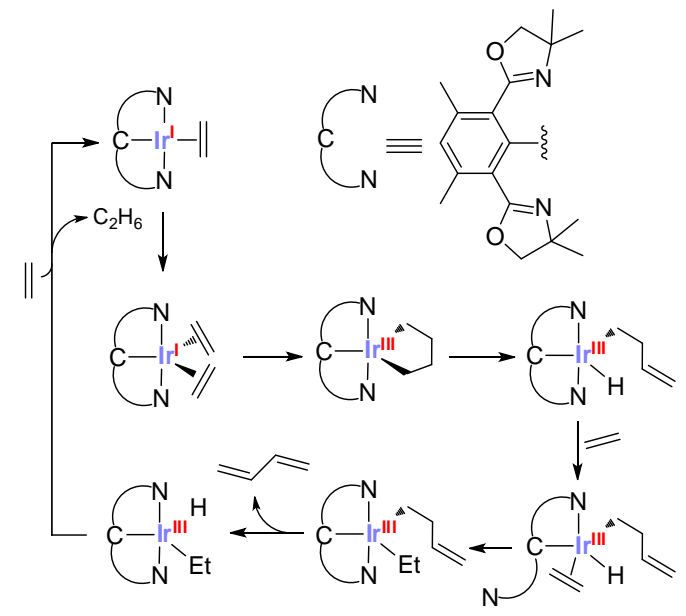

Scheme 45 - Mechanism followed by iridium catalyst to produce ethane and butadiene from ethylene.

\subsubsection{Molybdenum}

A similar reactivity has been observed with a molybdenum complex bearing a PDI ligand.[109] Indeed, reduction of (PDI) $\mathrm{MoCl}_{3}$ complex in the presence of 1-hexene, resulted in the formation of a 1,3hexadiene Mo complex together with liberation of hexane (Scheme 46, top). This result is rationalized in the case of ethylene by the formation of 1-butene via oxidative coupling of two ethylene followed by $\beta-\mathrm{H}$ transfer. In a subsequent step, $\mathrm{C}-\mathrm{H}$ bond insertion formed a $\mathrm{Mo}(\mathrm{alkyl})(\mathrm{H})$ complex, which can insert ethylene. From there, ethane is liberated by reductive elimination following another $\beta-\mathrm{H}$ elimination (Scheme 46, bottom).
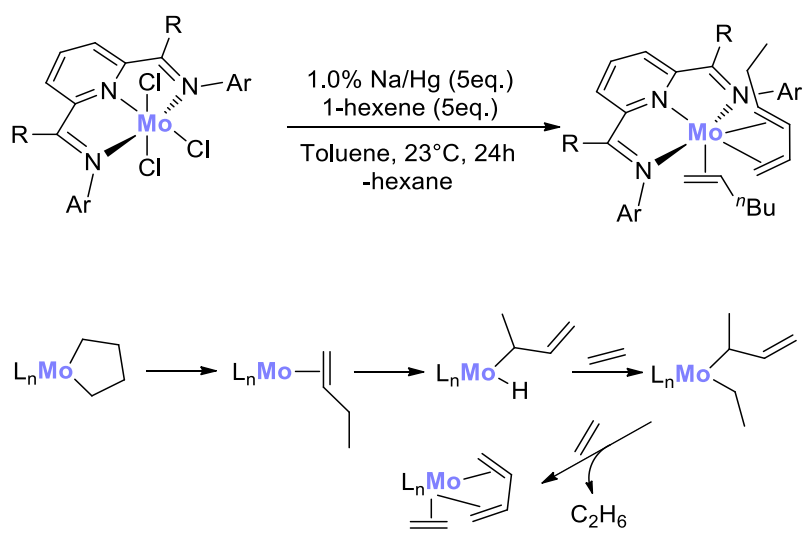

Scheme 46 - Top: reaction of reduced bis(imine)pyridine molybdenum complex with 1-hexene. Bottom: proposed mechanism after the formation of the metallacycle to form butadiene and ethane. 


\section{Conclusions}

The past 20 years have witnessed several mechanistic investigations towards oligomerization of ethylene. The formation of alkenes, cyclobutane derivates or butadiene can be achieved from different sets of metal/ligands. This review presented the different approaches used to determine the mechanisms to generate 1-butene, 1-hexene or 1-octene with early transition metals (Ti to Mo). The synthesis of metal alkyl complexes and reactions under mixtures of $\mathrm{C}_{2} \mathrm{D}_{4} / \mathrm{C}_{2} \mathrm{H}_{4}$ are the most compelling experiments to determine whether or not the mechanism involves metallacyclic intermediates. Later transition metals show distinct reactivity patterns towards alkenes. Although iron and cobalt catalysts are able to dimerize ethylene into 1-butene, the major outcome of the reaction is reported to be the cyclodimerization into cyclobutane derivatives. In these cases, the mechanism has been proven to be "metallacyclic" thanks to intermediate isolation. Nickel complexes, as iron and cobalt, are able to cyclodimerize or dimerize alkenes. While nickelacyclopentane complexes can be synthesized, no catalytic experiment has been shown to follow a metallacyclic mechanism. Finally, a new reactivity has been discovered recently, i.e. the dimerization of ethylene into butadiene. In the case of iridium, the mechanism has been determined by isolation of several intermediates while the mechanism followed by molybdenum is hypothetical.

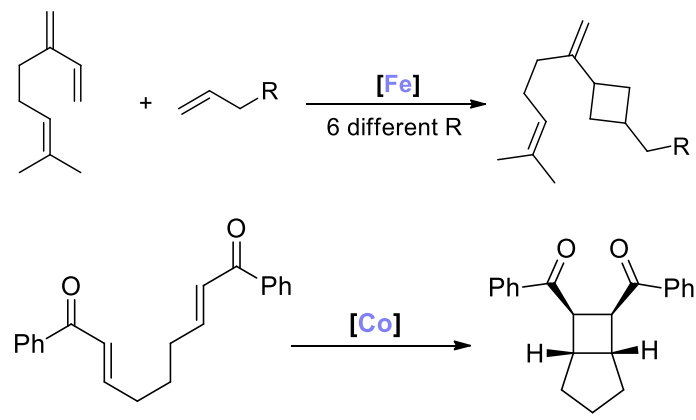

Scheme 47 - Original reactivities using Fe and Co catalysts following a metallacyclic mechanism.

In conclusion, oxidative coupling of two ethylene molecules to form a metallacycle is possible with all transition metals, but obviously is highly dependent on the ligand set. Such a possibility was extended to couple more functionalized substrates, opening avenues in synthetic organic chemistry. As an illustration, a cyclobutane moiety could be obtained from a myrcene backbone with a Fe complex,[99] as well as via internal cyclo-isomerization of an original bis-enone at Cobalt (Scheme 47).[110]

\section{Conflicts of interest}

The authors declare they have no known competing financial interests or personal relationships that could have appeared to influence the work reported in this paper.

\section{Acknowledgements}

We thank IFP Energies Nouvelles for financial support.

\section{Notes and references}

[1] H. Kühlhörn, H. Martin, K. Meyer, K. Nagel, H. Zosel, K. Sauer, H.G. Gellert, K. Ziegler, Angew. Chemie 12 (1952) 323-329.

[2] C.T. Young, R. von Goetze, A.K. Tomov, F. Zaccaria, G.J.P. Britovsek, Top. Catal. 63 (2020) 294-318.

[3] P. Cossee, J. Catal. 3 (1964) 80-88. 
[4] E.J. Arlman, J. Catal. 3 (1964) 89-98.

[5] J. Arlman, P. Cossee, J. Catal. 3 (1964) 99-104.

[6] J.R. Briggs, J. Chem. Soc. Chem. Commun. (1989) 674-675.

[7] O.L. Sydora, Organometallics 38 (2019) 997-1010.

[8] D.S. Mcguinness, Chem. Rev. 111 (2011) 2321-2341.

[9] P.-A.R. Breuil, L. Magna, H. Olivier-Bourbigou, Catal. Letters 145 (2015) 173-192.

[10] E. ichi Negishi, S.J. Holmes, J.M. Tour, J.A. Miller, F.E. Cederbaum, D.R. Swanson, T. Takahashi, J. Am. Chem. Soc. 111 (1989) 3336-3346.

[11] T. Takahashi, R. Fischer, Z. Xi, K. Nakajima, Chem. Lett. 5 (1996) 357-358.

[12] S. Mansel, D. Thomas, C. Lefeber, D. Heller, R. Kempe, W. Baumann, U. Rosenthal, Organometallics 16 (1997) 2886-2890.

[13] A. Bre, Y. Chauvin, D. Commereuc, New J. Chem. 10 (1986) 34-36.

[14] J.A. Suttil, D.S. McGuinness, Organometallics 31 (2012) 7004-7010.

[15] R. Robinson, D.S. Mcguinness, B.F. Yates, ACS Catal. 3 (2013) 3006-3015.

[16] C. Pellecchia, D. Pappalardo, G.J. Grute, Macromolecules 32 (1999) 4491-4493.

[17] P.J.W. Deckers, B. Hessen, J.H. Teuben, Angew. Chemie - Int. Ed. 40 (2001) 2516-2519.

[18] E. Otten, A.A. Batinas, A. Meetsma, B. Hessen, J. Am. Chem. Soc. 131 (2009) 5298-5312.

[19] P.J.W. Deckers, B. Hessen, J.H. Teuben, Angew. Chemie - Int. Ed. 40 (2001) 2516-2519.

[20] S. Tobisch, T. Ziegler, J. Am. Chem. Soc. 126 (2004) 9059-9071.

[21] T. De Bruin, P. Raybaud, H. Toulhoat, Organometallics 27 (2008) 4864-4872.

[22] T. Wu, Y. Qian, J. Huang, J. Mol. Catal. A Chem. 214 (2004) 227-229.

[23] Y. Zhang, H. Ma, J. Huang, J. Mol. Catal. A Chem. 373 (2013) 85-95.

[24] F.A. Pasha, J.M. Basset, H. Toulhoat, T. De Bruin, Organometallics 34 (2015) 426-431.

[25] Y. Suzuki, S. Kinoshita, A. Shibahara, S. Ishii, K. Kawamura, Y. Inoue, T. Fujita, Organometallics 29 (2010) 2394-2396.

[26] Y. Suzuki, S. Kinoshita, A. Shibahara, N. Yoshimura, I. Hara, T. Hamada, K. Kawamura, K. Tsurugi, Y. Saito, S. Ishii, Y. Nakayama, N. Matsukawa, (Mitsui Chemicals), Transition Metal Complex Compound, Olefin Oligomerization Catalyst Containing the Compound, and Method for Producing Olefin Oligomer Performed in the Presence of the Catalyst, EP 2174928 B1, 2010.

[27] A. Sattler, J.A. Labinger, J.E. Bercaw, Organometallics 32 (2013) 6899-6902.

[28] S. Ishii, T. Nakano, K. Kawamura, S. Kinoshita, S. Ichikawa, T. Fujita, Catal. Today 303 (2018) 263-270.

[29] A. Sattler, D.G. Vandervelde, J.A. Labinger, J.E. Bercaw, J. Am. Chem. Soc. 136 (2014) 10790-10800.

[30] A. Sattler, D.C. Aluthge, J.R. Winkler, J.A. Labinger, J.E. Bercaw, ACS Catal. 6 (2016) 19-22.

[31] I.E. Soshnikov, N. V. Semikolenova, J. Ma, K.Q. Zhao, V.A. Zakharov, K.P. Bryliakov, C. Redshaw, E.P. Talsi, Organometallics 33 (2014) 1431-1439.

[32] I.E. Soshnikov, N.V. Semikolenova, A.A. Antonov, K.P. Bryliakov, V.A. Zakharov, E.P. Talsi, Catal. Sustain. Energy 3 (2017) 1-10.

[33] F.F. Karbach, J.R. Severn, R. Duchateau, ACS Catal. 5 (2015) 5068-5076.

[34] D.K. Steelman, D.C. Aluthge, M.C. Lehman, J.A. Labinger, J.E. Bercaw, ACS Catal. 7 (2017) 4922-4926.

[35] T. Fujita, K. Kawai, Top. Catal. 57 (2014) 852-877.

[36] H. Terao, A. Iwashita, N. Matsukawa, S. Ishii, M. Mitani, H. Tanaka, T. Nakano, T. Fujita, ACS Catal. 1 (2011) 254-265.

[37] J.A. Suttil, M.F. Shaw, D.S. McGuinness, M.G. Gardiner, S.J. Evans, Dalt. Trans. 42 (2013) 9129-9138.

[38] H. Audouin, R. Bellini, L. Magna, N. Mézailles, H. Olivier-bourbigou, Eur. J. Inorg. Chem. (2015) 5272 5280 .

[39] A. Cordier, P.-A. Breuil, T. Michel, L. Magna, H. Olivier-Bourbigou, J. Raynaud, C. Boisson, V. Monteil, Catal. Sci. Technol. 10 (2020) 1602-1608.

[40] E.A.C. Brussee, A. Meetsma, B. Hessen, J.H. Teuben, Chem. Commun. 082 (2000) 497-498.

[41] S. Zhang, K. Nomura, J. Am. Chem. Soc. 132 (2010) 4960-4965.

[42] K. Nomura, T. Mitsudome, A. Igarashi, G. Nagai, K. Tsutsumi, T. Ina, T. Omiya, H. Takaya, S. Yamazoe, Organometallics 36 (2017) 530-542.

[43] K. Nomura, A. Igarashi, S. Katao, W. Zhang, W.H. Sun, Inorg. Chem. 52 (2013) 2607-2614.

[44] X. Tang, A. Igarashi, W. Sun, A. Inagaki, J. Liu, W. Zhang, Y. Li, K. Nomura, Organometallics 33 (2014) $1053-1060$.

[45] A. Igarashi, S. Zhang, K. Nomura, (2012) 1-7.

[46] A. Igarashi, S. Zhang, K. Nomura, Organometallics (2012) 3575-3581.

[47] K. Nomura, T. Mitsudome, A. Igarashi, G. Nagai, K. Tsutsumi, T. Ina, T. Omiya, H. Takaya, S. Yamazoe, 
Organometallics 36 (2017) 530-542.

[48] K. Nomura, T. Mitsudome, K. Tsutsumi, S. Yamazoe, J. Phys. Soc. Japan 87 (2018) 1-8.

[49] K. Nomura, Catalysts 9 (2019) 1016.

[50] J. Yi, N. Nakatani, K. Nomura, Dalt. Trans. 49 (2020) 8008-8028.

[51] C. Andes, S.B. Harkins, S. Murtuza, K. Oyler, A. Sen, J. Am. Chem. Soc. 123 (2001) 7423-7424.

[52] Z.X. Yu, K.N. Houk, Angew. Chemie - Int. Ed. 42 (2003) 808-811.

[53] R. Arteaga-Müller, H. Tsurugi, T. Saito, M. Yanagawa, S. Oda, K. Mashima, J. Am. Chem. Soc. 131 (2009) 5370-5371.

[54] Y. Chen, E. Callens, E. Abou-Hamad, N. Merle, A.J.P. White, M. Taoufik, C. Copéret, E. Le Roux, J.M. Basset, Angew. Chemie - Int. Ed. 51 (2012) 11886-11889.

[55] Y. Chen, J.-M. Basset, R. Credendino, E. Callens, M. Atiqullah, M.A. Al-Harthi, L. Cavallo, ACS Catal. 3 (2013) 1360-1364.

[56] A.M. Messinis, A.S. Batsanov, J.A.K. Howard, M.J. Hanton, P.W. Dyer, ChemCatChem 11 (2019) 17561764.

[57] M. Kuboki, K. Nomura, Organometallics 38 (2019) 1544-1559.

[58] A. Hamieh, R. Dey, B. Nekoueishahraki, M.K. Samantaray, Y. Chen, E. Abou-Hamad, J.M. Basset, Chem. Commun. 53 (2017) 7068-7071.

[59] O.L. Sydora, Organometallics 38 (2019) 997-1010.

[60] A.J. Rucklidge, D.S. McGuinness, R.P. Tooze, A.M.Z. Slawin, J.D.A. Pelletier, M.J. Hanton, P.B. Webb, Organometallics 26 (2007) 2782-2787.

[61] L.E. Bowen, M.F. Haddow, A.G. Orpen, D.F. Wass, J. Chem. Soc. Dalt. Trans. 4 (2007) 1160-1168.

[62] T. Agapie, S.J. Schofr, J.A. Labinger, J.E. Bercaw, S.J. Schofer, J.A. Labinger, J.E. Bercaw, J. Am. Chem. Soc. 126 (2004) 1304-1305.

[63] T. Agapie, J.A. Labinger, J.E. Bercaw, J. Am. Chem. Soc. 129 (2007) 14281-14295.

[64] D.H. Kwon, J.T. Fuller, U.J. Kilgore, O.L. Sydora, S.M. Bischof, D.H. Ess, ACS Catal. 8 (2018) 11381142.

[65] N.A. Hirscher, D. Perez Sierra, T. Agapie, J. Am. Chem. Soc. 141 (2019) 6022-6029.

[66] L. Liu, Z. Liu, S. Tang, R. Cheng, X. He, B. Liu, ACS Catal. 9 (2019) 10519-10527.

[67] S. Licciulli, I. Thapa, K. Albahily, I. Korobkov, S. Gambarotta, R. Duchateau, R. Chevalier, K. Schuhen, Angew. Chemie - Int. Ed. 49 (2010) 9225-9228.

[68] D.H. Kwon, S.M. Maley, J.C. Stanley, O.L. Sydora, S.M. Bischof, D.H. Ess, ACS Catal. (2020) 9674-9683.

[69] S.M. Maley, D.-H. Kwon, N. Rollins, J.C. Stanley, O.L. Sydora, S.M. Bischof, D.H. Ess, Chem. Sci. 11 (2020) 9665-9674.

[70] R. Grauke, R. Schepper, J. Rabeah, R. Schoch, U. Bentrup, M. Bauer, A. Brückner, ChemCatChem 12 (2019) 1025-1035.

[71] N.A. Hirscher, C.H. Arnett, P.H. Oyala, T. Agapie, Organometallics 39 (2020) 4420-4429.

[72] N.A. Hirscher, T. Agapie, Organometallics 36 (2017) 4107-4110.

[73] B. Venderbosch, L.A. Wolzak, J.P.H. Oudsen, B. De Bruin, T.J. Korstanje, M. Tromp, Catal. Sci. Technol. 10 (2020) 6212-6222.

[74] B. Venderbosch, J.P.H. Oudsen, D.J. Martin, B. de Bruin, T.J. Korstanje, M. Tromp, ChemCatChem 12 (2020) 881-892.

[75] P.-A.R. Breuil, L. Magna, H. Olivier-Bourbigou, Catal. Letters 145 (2015) 173-192.

[76] H. Olivier, P. Laurent-Gérot, J. Mol. Catal. A Chem. 148 (1999) 43-48.

[77] S. Tobisch, Organometallics 26 (2007) 6529-6532.

[78] S. Tobisch, J. Chem. Soc. Dalt. Trans. (2008) 2120-2127.

[79] M.J. Hanton, L. Daubney, T. Lebl, S. Polas, D.M. Smith, A. Willemse, Dalt. Trans. 39 (2010) 7025-7037.

[80] C.M.R. Wright, Z.R. Turner, J.C. Buffet, D. O’Hare, Chem. Commun. 52 (2016) 2850-2853.

[81] A.M. Messinis, W.R.H. Wright, A.S. Batsanov, J.A.K. Howard, M.J. Hanton, P.W. Dyer, ACS Catal. 8 (2018) 11235-11248.

[82] A.M. Messinis, A.S. Batsanov, W.R.H. Wright, J.A.K. Howard, M.J. Hanton, P.W. Dyer, ACS Catal. 8 (2018) 11249-11263.

[83] C.S. Cundy, M. Green, F.G.A. Stone, J. Chem. Soc. A (1970) 1647-1653.

[84] R.R. Burch, J.C. Calabrese, S.D. Ittel, Organometallics 7 (1988) 1642-1648.

[85] M. Ohashi, T. Kawashima, T. Taniguchi, K. Kikushima, S. Ogoshi, Organometallics 34 (2015) 1604-1607.

[86] F. Bernardi, A. Bottoni, I. Rossi, J. Am. Chem. Soc. 120 (1998) 7770-7775.

[87] R.H. Grubbs, A. Miyashita, M.-I.M. Liu, L. Burk, Patrick, J. Am. Chem. Soc. 100 (1978) 2418-2425.

[88] R.H. Grubbs, A. Miyashita, M.-I.M. Liu, L. Burk, Patrick, J. Am. Chem. Soc. 99 (1977) 3863-3864. 
[89] R.H. Grubbs, A. Miyashita, J. Am. Chem. Soc. 100 (1978) 1300-1302.

[90] R.H. Grubbs, A. Miyashita, J. Am. Chem. Soc. 100 (1978) 7416-7418.

[91] E. Moser, E. Jeanneau, N. Mézailles, H. Olivier-Bourbigou, P.A.R. Breuil, Dalt. Trans. 48 (2019) 41014104.

[92] R. Lhermet, E. Moser, E. Jeanneau, P. Breuil, H. Olivier-bourbigou, Chem. - A Eur. J. 23 (2017) 74337437.

[93] J. Zhang, S. Liu, A. Li, H. Ye, Z. Li, New J. Chem. 40 (2016) 7027-7033.

[94] S. Mukherjee, B.A. Patel, S. Bhaduri, Organometallics 28 (2009) 3074-3078.

[95] A. Buchard, A. Auffrant, C. Klemps, L. Vu-Do, L. Boubekeur, X.F.L. Goff, P. Le Floch, Chem. Commun. (2007) 1502-1504.

[96] V. Tognetti, A. Buchard, A. Auffrant, I. Ciofini, P. Le Floch, C. Adamo, J. Mol. Model. 19 (2013) $2107-$ 2118.

[97] M.W. Bouwkamp, A.C. Bowman, E. Lobkovsky, P.J. Chirik, J. Am. Chem. Soc. 128 (2006) 13340-13341.

[98] J.M. Hoyt, K.T. Sylvester, S.P. Semproni, P.J. Chirik, J. Am. Chem. Soc. 135 (2013) 4862-4877.

[99] J.M. Hoyt, V.A. Schmidt, A.M. Tondreau, P.J. Chirik, Science (80-. ). 349 (2015) 960-963.

[100] L. Hu, H. Chen, J. Am. Chem. Soc. 139 (2017) 15564-15567.

[101] M. V. Joannou, J.M. Hoyt, P.J. Chirik, J. Am. Chem. Soc. 142 (2020) 5314-5330.

[102] A.C. Bowman, C. Milsmann, C.C.H. Atienza, E. Lobkovsky, K. Wieghardt, P.J. Chirik, J. Am. Chem. Soc. 132 (2010) 1676-1684.

[103] V.A. Schmidt, J.M. Hoyt, G.W. Margulieux, P.J. Chirik, J. Am. Chem. Soc. 137 (2015) 7903-7914.

[104] P. Binger, G. Schroth, Angew. Chemie - Int. Ed. - Int. Ed. 13 (1974) 465-466.

[105] M.J. Doyle, J. McMeeking, P. Binger, J. Chem. Soc. Chem. Commun. (1976) 376-377.

[106] P. Binger, 135 (1977) 405-414.

[107] P. Binger, M.J. Doyle, C. Krüger, Y. Tsay, Z. Naturforsch. 34b (1979) 1289-1292.

[108] Y. Gao, T.J. Emge, K. Krogh-Jespersen, A.S. Goldman, J. Am. Chem. Soc. 140 (2018) 2260-2264.

[109] M. V. Joannou, M.J. Bezdek, K. Al-Bahily, I. Korobkov, P.J. Chirik, Organometallics 36 (2017) 42154223.

[110] L.C. Wang, H.Y. Jang, Y. Roh, V. Lynch, A.J. Schultz, X. Wang, M.J. Krische, J. Am. Chem. Soc. 124 (2002) 9448-9453. 